\title{
21
}

\section{Fracture Analog of the Sub-Andean Devonian of Southern Bolivia: Lidar Applied to Abra Del Condor}

\section{David García-Sellés, Oscar Gratacós, Pablo Granado, Núria Carrera, and Josep Anton Muñoz}

Institut de Recerca Geomodels, Departament de la Terra i l'Oceà, Facultat de Ciències de la Terra, Universitat de Barcelona, Barcelona, C/Martí Franques s/n, 08028,Spain (e-mails; dgarcia@ub.edu; ogratacos@ub.edu; pablomartinez_granado@ub.edu; nuriacarrera@ub.edu; jamunoz@ub.edu)

\section{Sergio Sarmiento}

Repsol Technical Services, 2455 Technology Forest Blvd, The Woodlands 77381, Texas, U.S.A. (e-mail: sergio .sarmiento@repsol.com)

\section{R. Lakshmikantha}

Repsol Technology Centre, C/ Agustín de Betancourt s/n, Mostoles 28935, Madrid, Spain (e-mail: m.lakshmikantha@repsol.com)

\section{Juan Carlos Cordova}

Repsol YPF Bolivia, Av. Las Ramblas 100, ITC Tower, Santa Cruz de la Sierra, Bolivia (e-mail: cordova .salinas.juancarlos@repsol.com)

\section{ABSTRACT}

Tight fractured sandstones of the Devonian Huamampampa Formation are associated with large gas discoveries in the sub-Andean fold-and-thrust belt of southern Bolivia. ALIDAR-based fracture characterization of the Abra del Condor backlimb anticline, a structuralstratigraphic analog, is used as the basis for a fracture stratigraphy determination. Fracture characterization using LIDAR is integrated with outcrop scanlines and is framed by stratigraphy and structural positions within this thrust-related anticline. SEFL software was used to process LIDAR data, dividing the outcrop by orientations. A workflow to extract modeled fracture planes and their associated orientations, lengths, and heights results in five fracture sets, partially validated by fracture outcrop scanlines. Multiple virtual scanlines are used to measure fracture intensity, identify fracture stratigraphic units, and define fracture-associated parameters of abundance and size distribution.

Our LIDAR-based fracture characterization indicates a distribution of fracture intensities according to their structural position, decreasing from the hinge to the backlimb. From the five fracture sets identified, one set of orthogonal fractures dominates. Moreover, most of the fractures are contained or bounded within their fracture stratigraphic units and calculated fracture spacing ratio and the fracture space index show a nonexistent relation between fracture spacing and the fracture stratigraphic unit thickness. 


\section{INTRODUCTION}

Outcrops of the Devonian Huamampampa Formation at the Abra del Condor area (Figures 1,2) offer the opportunity to study a natural fractured reservoir analog, which plays an important role in the modeling of the hydrocarbon fields of the Subandean ranges of Argentina and Bolivia. The Abra del Condor area is located $60 \mathrm{~km}(37 \mathrm{mi})$ west of some of the giant gas fields producing from this reservoir. Previous work shows that most of the near-surface fractures can be identified and counted and that the property and fracture attributes between the outcrop and the subsurface are close enough, making the outcrops excellent analogs for the subsurface (Iñigo, 2009).

The study location is within the outcrops of the Abra del Condor anticline, which was formed in a fold-andthrust belt tectonic setting. Fractured sandstones of
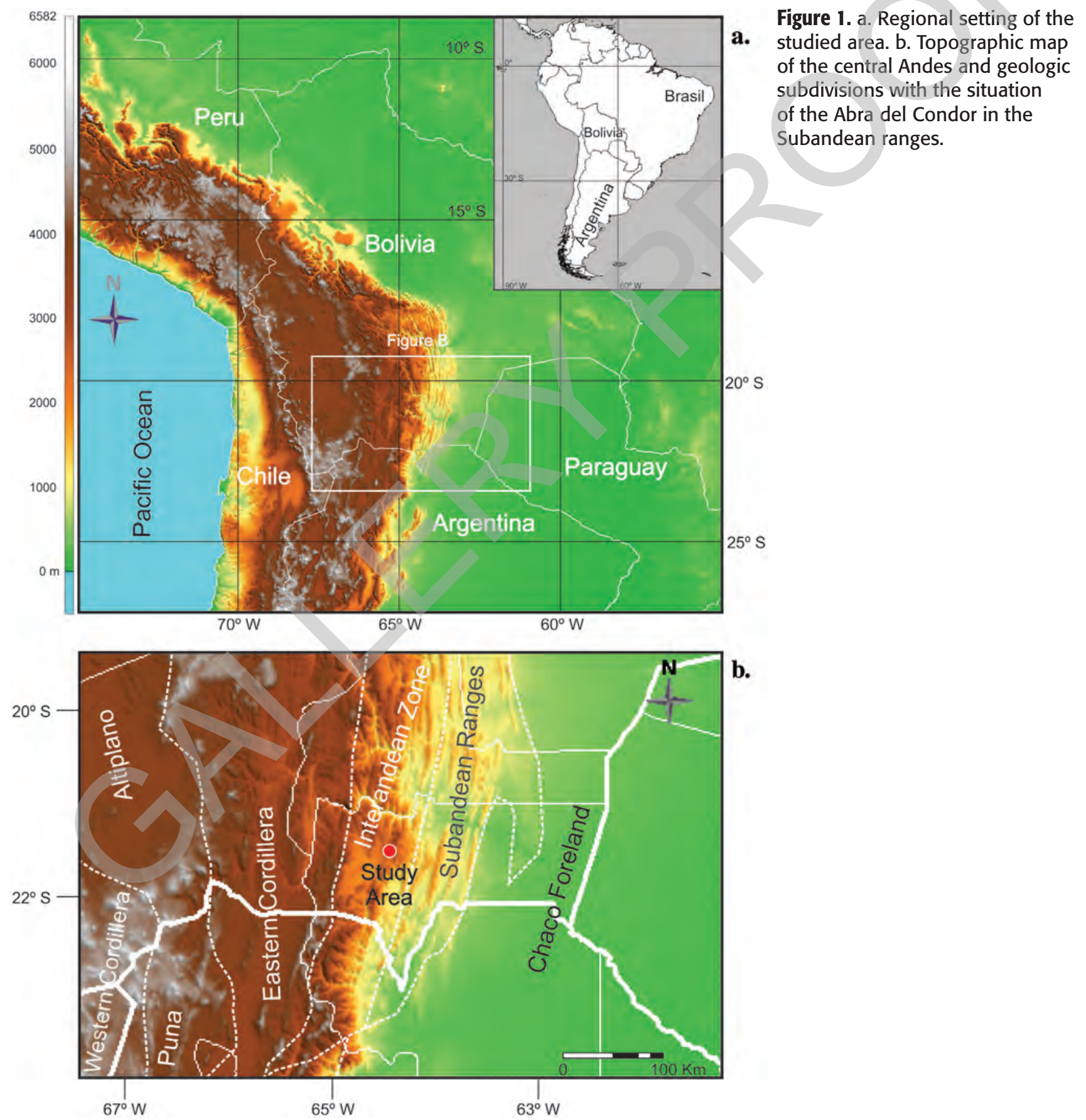


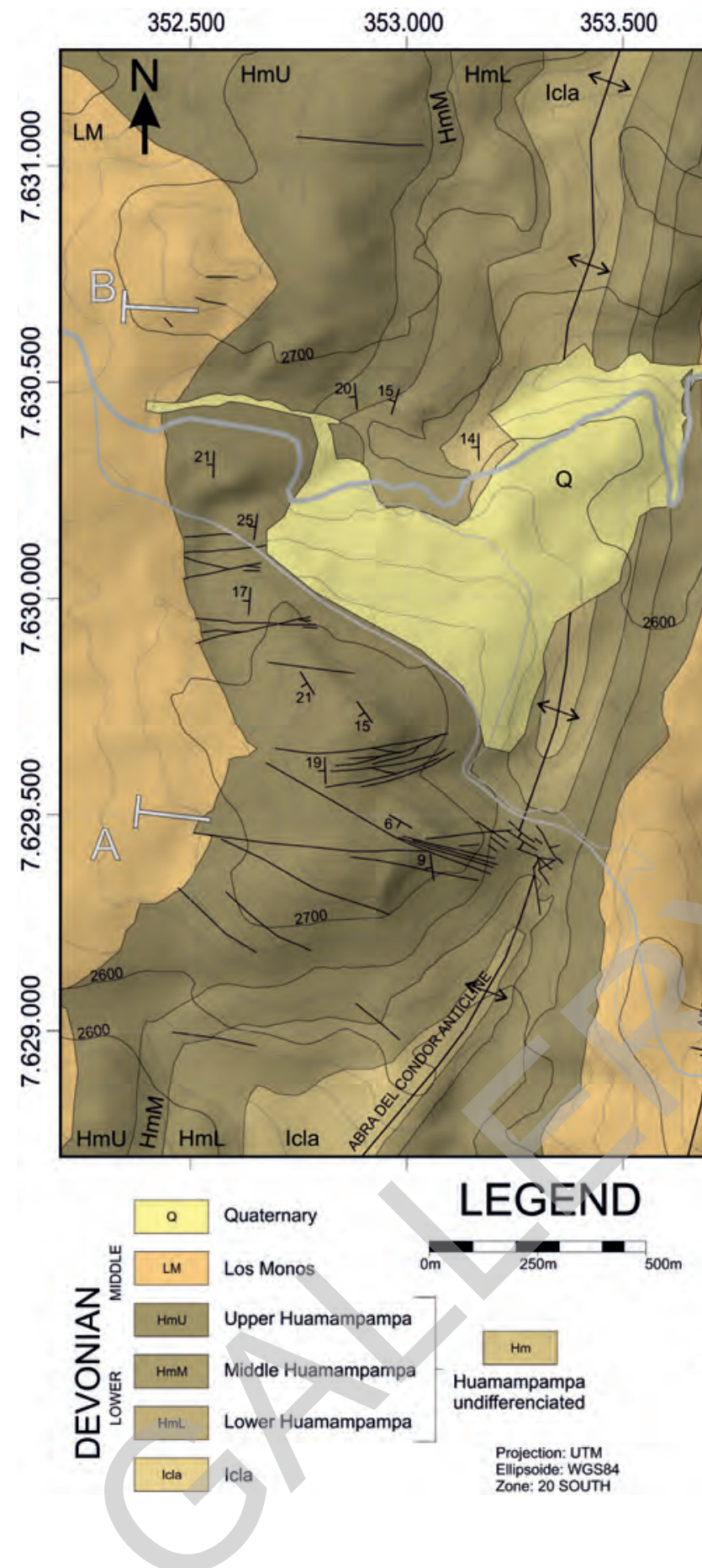

the Huamampampa Formation are exposed dozens of kilometers along the backlimb of the structure in small cliffs. Zapata and Araujo (2003) established a comparison between the outcrop and the easterly sub-Andean reservoirs, and Florez-Niño et al. (2005) described and proposed an interpretative model of faults and fractures. Iñigo (2009) and Iñigo et al. (2012) focused their work on the characterization of microfracture apertures. Additionally, the sub-Andean ranges have been
Figure 2. Geological map of the western sector of the Piedra Larga thrust sheet, focused at the hinge and backlimb of the subsidiary fold of the Abra del Condor anticline. The map includes the geological crosssection situation (Figure 3), stratigraphic formation boundaries, and the main tectonic structures. of structural, stratigraphic, and mineralogical interest by other authors (Baby et al., 1992; Kley et al., 1996; Labaume et al., 2001; Moretti et al., 2002; Echavarria et al., 2003; Rocha and Cristallini, 2015). The exposed Devonian Huamampampa Formation is composed of quartzitic sandstones with primary porosity values less than 2\% (Moretti et al., 2002; Iñigo, 2009), but it is affected by natural fracture systems that enhance the effective permeability (Zapata and Araujo, 2003). 
Following the terminology of Peacock et al. (2016), natural fractures are mechanical breaks in rocks that contain displacement discontinuities across surfaces or narrow zones. They are subdivided into faults, when they have their movement parallel to their surfaces, and opening-mode fractures, when they show displacement normal to their surfaces (Hancock, 1985; Pollard and Aydin, 1988). Opening-mode fractures are termed veins or joints depending on the amount of mineral deposits within them. Fractures in Huamampampa Formation cores are quartz and calcite-lined openingmode fractures and small faults (Iñigo et al., 2012). Natural fractures form and propagate when failure criteria are met. Therefore, understanding natural fractures is fundamental to modeling the Subandean range reservoirs and to delineate the high productivity areas.

This study aims to be a quantitative evaluation of the fracture pattern in the Abra del Condor anticline, across an area of about $1.7 \mathrm{~km}(1 \mathrm{mi})$ by $1 \mathrm{~km}(0.6 \mathrm{mi}$; Figure 2). The study was carried out by means of Light Detection and Ranging (LIDAR) and its applicability to fracture characterization (Sturzenegger and Stead, 2009; Seers and Hodgetts, 2014). LIDAR technology consists of a Terrestrial Laser Scanner (TLS) device that captures the topographic surface of outcrops through points and creates a high resolution digital outcrop model (HRDOM; Slob et al., 2005). Surface shapes are represented with more detail according to the scan densities, usually one point each few centimeters. HRDOMs contain fracture surfaces with sufficient detail to capture and reconstruct them digitally, keeping most of their geometrical characteristics (García-Sellés et al., 2011; Santana et al., 2012).

The presented workflow is related to the detection, measurement, and modeling discontinuities as they are related to fractures. State-of-the-art methods are applied in this study, based on recent developments in TLS fracture measurements (García-Sellés et al., 2016). To this end, we produced a virtual fracture model and used it to characterize the spatial distribution of fractures in rock masses at the Abra del Condor outcrop.

\section{Parameters in Fracture Characterization}

Individual fractures are characterized by the coordinates of their surface central position or centroid, fracture length, height and area, aperture (undetectable with this methodology), and surface orientations grouped by orientation set (Priest, 1993). Moreover, at the rock mass characterization level, the relationship of the individual fractures is determined by four factors: (1) the spacing between fracture sets; (2) the coefficient of variation level of fracture clustering (Gillespie et al., 1999); (3) mean values of length, height, and area as well as their frequency distributions, which reflect their best fit function (Bonnet et al., 2001); and (4) the parameters to describe the amount of fracturing (Dershowitz and Herda, 1992).

Virtual fracture model is used to calculate the amount of fracturing for the rock mass, using a term called "fracture abundance," as proposed by Dershowitz and Herda (1992). The fracture is described as density, intensity, and porosity, where each parameter describes different concepts along a line (1-D), an area (2-D) and a volume (3-D). The concept measured in density is the number of fractures: $\mathrm{P}_{10}, \mathrm{P}_{20}$, and $\mathrm{P}_{30}$; in intensity it is the number of fractures with an attribute of dimension, a number of centroids (1-D), length of fracture traces (2-D), and area of fractures (3-D): $\mathrm{P}_{10}, \mathrm{P}_{21}$, and $\mathrm{P}_{32}$. Porosity is used when the fracture aperture is present to calculate the percentage of fracture space in a rock mass: $\mathrm{P}_{11}, \mathrm{P}_{22}$, and $\mathrm{P}_{33}$. These measurements depend on the sampled scanline or area orientation, with the exception of the $P_{32}$ value. $\mathrm{P}_{32}$ measures the fracture area per unit of volume. This parameter cannot be directly measured from the outcrop surface and must be calculated indirectly from the extrapolation of other abundance measurements (Wang, 2005).

The methodology applied in the virtual fracture model measures the fracture intensity, parallel to bedding every $10 \mathrm{~cm}$ (4 in.), allowing the recognition of vertical changes in intensity trends and the establishment of limits for fracture stratigraphic units (Laubach et al., 2009). The term "fracture stratigraphy," superseded and redefined from the previous usage (Hanks et al., 1994) by Laubach et al. (2009), is used to subdivide the rock mass in units based on fracture attributes. Rock heterogeneities plus bedding, faults, and strata are the points of growth for fracture development, which are triggered by changes in stress affecting the rock mechanical properties (Gross, 1993). Nelson (2001) identified lithology, grain size, porosity, bed thickness, and structural position as the geological factors that control the mechanical properties of the rock. Burial, diagenesis, or tectonic processes can also modify the mechanical properties of the rock mass from their original depositional condition to those existing at the time of fracturing, such that presentday mechanical properties may differ from those existing at the time of fracturing (Laubach et al., 2009), although mechanical layer transitions are commonly associated with major differences in fracture patterns (Ferrill et al., 2014, 2017).

These units are used to measure properties along the virtual scanlines and virtual window samples. From the virtual fracture model, the vertical 
persistence is also measured (Petit et al., 1994; Gillespie et al., 2001) for each fracture stratigraphic unit, where it is determined by the percentage of fractures that cross the unit boundaries or the stratabound properties of the fracture set. In this way, fracture spacing ratio (FSR; Gross, 1993) is measured, dividing the fracture stratigraphic unit thickness per the median fracture set spacing with the aim to find a correlation between confined fractures in the fracture stratigraphic unit and the fracture spacing index (FSI; Narr and Suppe, 1991). FSI corresponds to the slope measurement of the line with the best fit for the plotted relation between fracture stratigraphic unit thickness and joint spacing. In this study, fracture intensity is measured and used as an attribute to identify fracture stratigraphic units (Bertotti et al., 2007; García-Sellés et al., 2016).

Fractures surveyed by TLS correspond to those exposed completely or partially over the outcrop surface and therefore are conditioned by the outcrop orientation. Virtual scanlines are 2-D measurements constrained by the outcrop orientation. For this reason, the Abra del Condor outcrop has been divided into sectors, according to its surface orientation. Results are also analyzed and presented in that manner. Accordingly, measurements are presented as data set populations by sector, by fracture set, and by fracture stratigraphic units, with the aim to characterize fractures as precisely as possible and to constrain the relations between fractures and structural settings, stratigraphic or diagenetic processes.

\section{GEOLOGICAL SETTING}

The studied area corresponds to the Abra del Condor, an area located at the transition between the Eastern Cordillera to the west and the sub-Andean ranges to the east (Figure 1b) about $30 \mathrm{~km}$ (19 mi) east of Tarija. The boundary between these zones is marked by the eastern limit of the Lower Paleozoic outcrops and is referred to as the inter-Andean zone (Schmitz and Kley, 1997). The geological structure along these units has been interpreted as related to two major basement-involved thrusts, namely the inter-Andean and the sub-Andean thrusts (Kley et al., 1996; Schmitz and Kley, 1997). Andean shortening began in the late Oligocene and was transmitted eastward to the sub-Andean thrust not before 10 Ma (e.g., Dunn et al., 1995; Echavarria et al., 2003). The sub-Andean thrust uplifted the Interandean zone on top of an imbricate basement sheet and caused the development of the sub-Andean ranges. The sub-Andean ranges of southern Bolivia is a $150-\mathrm{km}$ (93-mi) wide and up to 400-km (249-mi) long active thin-skinned fold-and-thrust belt constituted of a series of north-north-northeast striking narrow thrust-related anticlines. The fold-and-thrust belt presents two major linked detachment levels: a lower one within the Silurian shales of the Kirusillas Formation and an upper one along the overpressured shales of the Los Monos Formation, which also constitutes the main source rock (e.g., Moretti et al., 1996; Cruz et al., 2008) for the hydrocarbons trapped in the Subandean ranges' thrust-related folds. Additional secondary detachments are located in the Devonian Icla Formation and within Triassic evaporitic formations (e.g., Dunn et al., 1995).

The Abra del Condor area displays a relatively simple structure, which consists from west to east of the Abra del Condor anticline, the Abra del Condor syncline (Figures 2, 3,4), and further to the east of the Piedra Larga anticline. These folds are part of the large Piedra Larga thrust sheet and are locally affected by smaller thrust faults. The Abra del Condor anticline is a highly asymmetric, doubly plunging fold that trends N198E; it is considered to be perpendicular to the prevailing east-west-directed Andean orogenic shortening (Figure 3). The upright-to-overturned bedding of the eastern limb of the Abra del Condor anticline (Figures 2, 3; Profile A-A') belongs to the strongly fractured mica-rich quartzites of the upper section of the Huamampampa Formation. The backlimb dips gently between $15^{\circ}$ up to $30^{\circ}$ toward the west and is separated by a flat lying hinge panel.

\section{Stratigraphy}

The studied stratigraphic units in the Abra del Condor belong to the so-called Cordilleran cycle of Bolivia (Lohman, 1970). The cycle was predominantly deposited in shallow marine to deltaic environments (Isaacson and Sablock, 1987) and displays a composite thickness of around $3.8 \mathrm{~km}$ (2.4 mi; Dunn et al., 1995). The cycle starts with a coarse clastic unit belonging to the Silurian Cancañiri Formation (Crowell et al., 1981; Toro, 1994; Sempere, 1995; Suárez-Soruco, 1995). This unit is followed by the Silurian Kirusillas Formation, a shale unit that grades upward to the transitional Guayabillas Formation and the quartzarenites, finegrained conglomeratic sandstones, and oligomictic conglomerates of the Devonian Santa Rosa Formation, which define a fan delta environment (Vistalli, 1999; Albariño et al., 2002). The remaining Devonian succession is represented by the black shale and quartzose sandstone packages from the Icla Formation, with a thickness of $500 \mathrm{~m}$ (1640 ft) corresponding to distal platform environments that move into a proximal platform (Vistalli, 1999). Concordantly above, the Huamampampa Formation is made of quartzose 

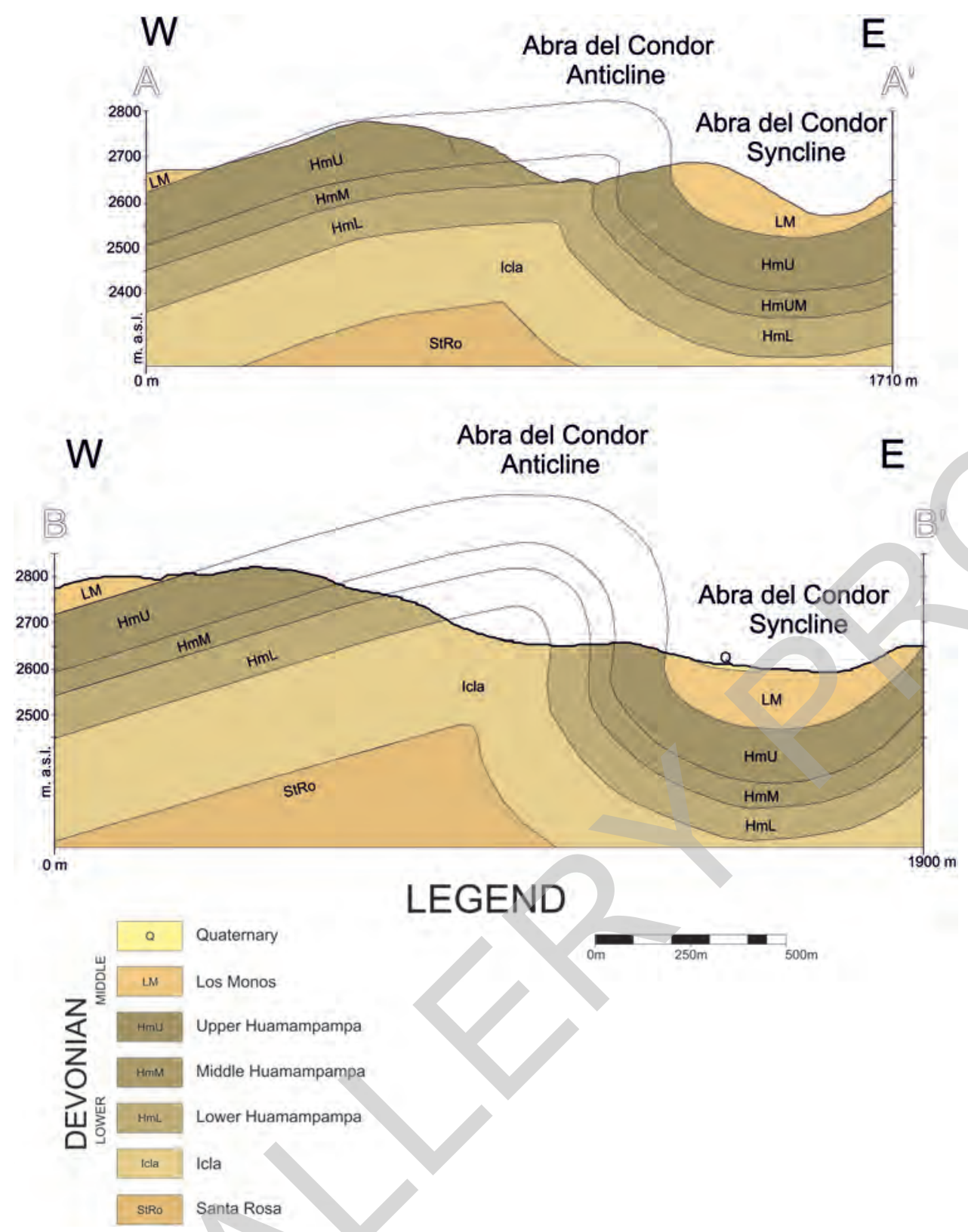

Figure 3. a. Southern crosssection across the central sector of the Abra del Condor anticline. The upper section of the Huamampampa Formation is exposed along this cliff in a propitious orientation for the study and scanning of the fractures. b. Northern cross-section. The sandstones of the lower section of the Huamampampa Formation offer the correct exposure for the application of this methodology. The middle section of the Huamampampa Formation, with a predominance of shales, is not favorable to the development of large fracture surfaces. The average bedding dip in the hinge of the anticline is $0^{\circ}$, increasing to $25^{\circ}$ to the west at the backlimb. Both profiles validate the thickness of each Huamampampa section.

sandstones and shales from distal platform environments to proximal platform deposits with coastal sandstones at the top. In an informal way, the Huamampampa Formation is divided into three sections attending to their mechanical properties, reflected in the geomorphological landscape (Figures 2, 3, 4). The lower section of the Huamampampa Formation is constituted predominantly by hard sandstones and the upper section by more friable sandstones (Iñigo et al., 2012), whereas the shales are predominant in the middle section. The overlying Los Monos Formation is constituted by dark shales that correspond to distal platform environments with interbedded sandstones.
The above-lying Iquiri Formation is also represented by sandstones and shales. The Icla and Los Monos Formations are shale dominated, and the Huamampampa and Iquiri Formations are sandstone dominated, with the former being the most important reservoir of the Subandean fold-and-thrust belt.

\section{METHODOLOGY}

It is a necessary condition in this workflow to have a HRDOM where fractures are sufficiently represented to be identified, extracted, and modeled in a virtual 


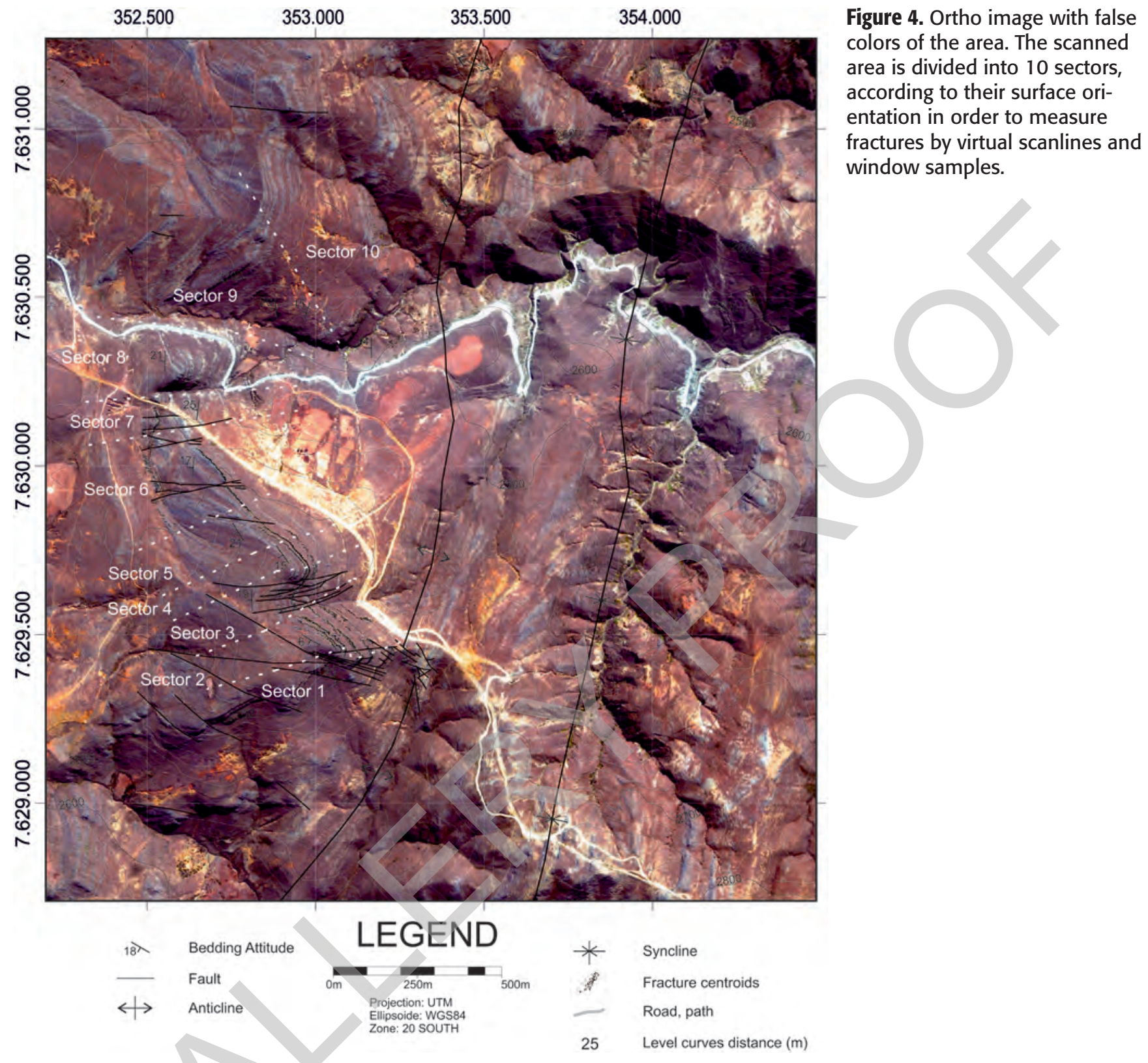

fracture model. In the study, the HRDOM was created with the data captured by the TLS model ILRIS 3D ${ }^{\circledR}$, from Optech Coop. from 27 stations equipped with a Differential Global Position System (D-GPS). The positional information is used to rotate and translate the HRDOM with 150 million points to the universal transverse mercator (UTM) reference system with an accuracy of less than $10 \mathrm{~cm}$ (4 in.). Fractures can be observed exposed at the outcrop, directly showing their surface, or also as traces from their intersection with the outcrop surface. For the last case, these fractures are undetectable with this methodology. The HRDOM is processed using the semiautomatic methodology described by García-Sellés et al. (2011) to detect and capture fracture surfaces, vectorizing the data point. During the process, the applied algorithms calculate the degree of coplanarity and collinearity for each TLS data point in order to obtain its position with respect to a planar surface. The vectorized points belonging to a surface of the same fracture are grouped into individual clusters and converted into planes (Figure 5; Santana et al., 2012). The planes maintain the geometrical properties (length, height, and area), position (through the central point or centroid), and orientation. These sets of planes and properties form the virtual fracture model. 
SECTOR 8

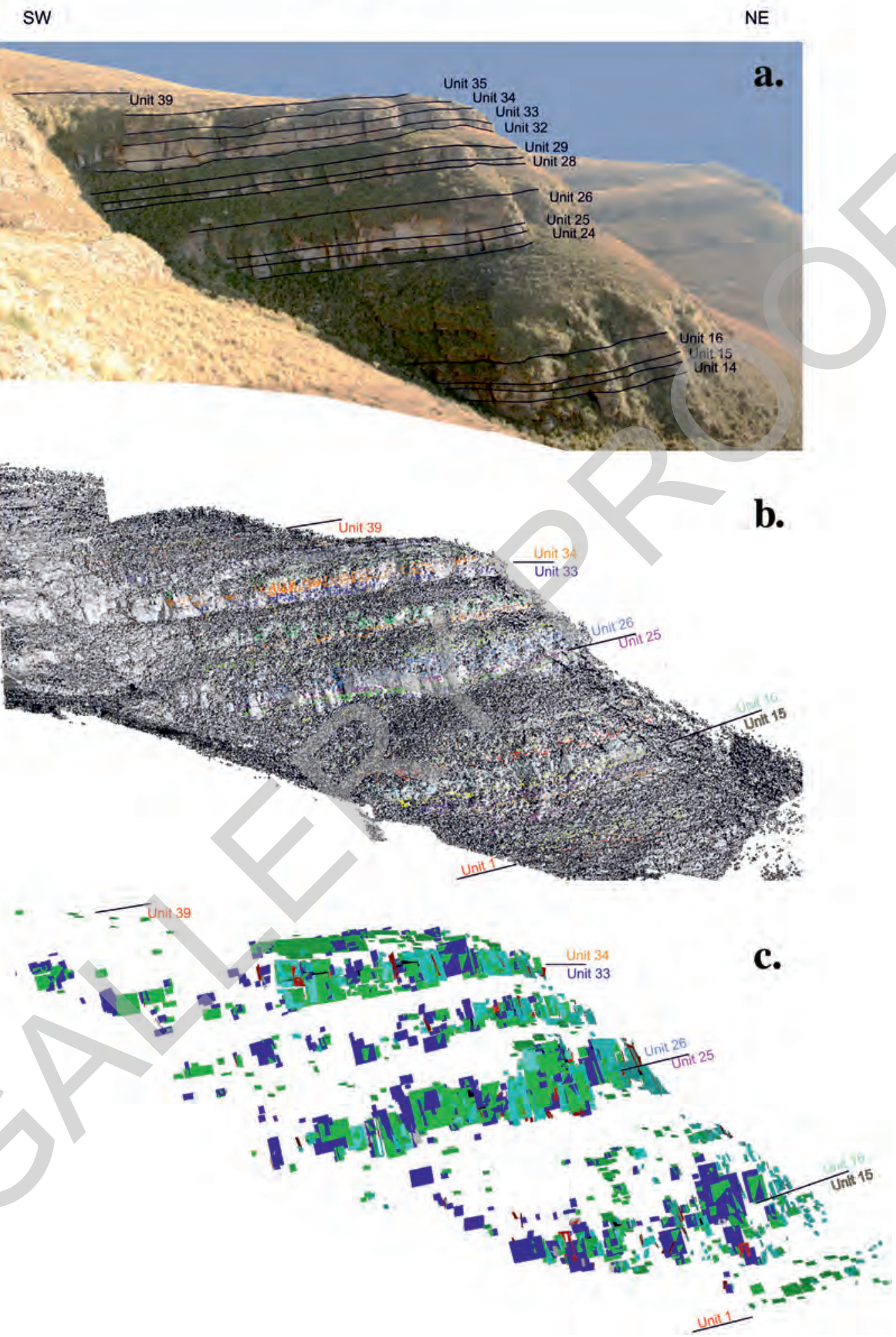

Figure 5. a. South view of sector 8 with the fracture stratigraphy units identified by differences according to the fracture intensity attribute. b. TLS data image with the fracture centroids; each color corresponds to a different fracture stratigraphy unit. c. Reconstructed fractures after application of the methodology. Each fracture set is represented by different colors (fracture set I in blue, set II in red, and set V in green). 
Once the fractures have been detected and modeled in the virtual fracture model, then they can be correlated with the fracture orientation sets identified in the outcrop. The final analysis of the fracture orientation sets may use the virtual fracture model, the outcrop scanlines, or both.

Some measurements, as parameters that relate individual fractures and their reliability, depend on the scanline length and the number of fractures being representative. Scanline measurements must be taken perpendicularly to the fracture orientation, but the outcrop orientation normally is not adequate. In addition, the methodology is based on the detection of fracture surfaces' censored fractures exposed by traces. Those fractures exposed obliquely with regard to the outcrop orientation are favorable to the processing methodology. A high number of detected fractures and an adequate outcrop orientation with respect to the fracture orientations offer the most reliable measurements. The Abra del Condor outcrop has been divided into 10 sectors (sectors 1 to 8 in the upper section of the Huamampampa Formation and sectors 9 and 10 in the lower section) in accordance with the orientations of the scanning outcrop surface (Figure 4).

\section{Fracture Stratigraphic Units}

Fracture intensity is measured from the virtual fracture model for each sector by multiple virtual scanlines separated vertically $10 \mathrm{~cm}$ (4 in.) from each other while covering the complete thickness of each outcrop. Fracture intensity values are represented in profiles for each sector of the upper and lower sections of the Huamampampa Formation (Figures 6, 7). Fracture spatial distribution is analyzed to identify mechanical units with similar fracture distributions that lead to a new fracture stratigraphic unit. These profiles show that the fracture stratigraphic units are observed across sectors with small changes in thickness.

\section{Scanlines}

Two different types of scanline measurements were performed to characterize fractures in the outcrop. First, the outcrop scanlines were defined with compass and tape as a part of the fieldwork (Priest, 1993) to measure fracture properties. Overall, six scanlines were surveyed at the top of the bedding surfaces in sector 6 (Figure 4) measuring fracture orientation, length, and aperture. The second type of scanline measurement corresponds to the so-called virtual scanlines where the methodologies proposed by Priest (1993) for fracture samples in the field are implemented in order to be applied for the virtual fracture model (García-Sellés et al., 2016). The outcrop scanlines consist of measuring geometrical fracture properties along a parallel bedding line. Thereby, the virtual model is implemented by re-creating the outcrop surface with the virtual fractures, and measurements are taken along parallel bedding planes that intersect these fractures. In this way, the parallel bedding planes correspond to the scanlines. The parameters measured with the virtual scanline in each sector and for each respective fracture stratigraphic unit and fracture orientation set are:

- number of fractures;

- mean height, length, and fracture area;

- mean spacing between fractures, coefficient of variation (Gillespie et al., 1999); and

- measures of abundance (Dershowitz and Herda, 1992): $P_{10}, P_{11}$ (with fracture aperture available).

\section{Virtual Window Sample Measurements}

The window sample technique proposed by Priest (1993) consists of measuring the fracture geometric properties over an area of an outcrop surface. In the virtual window sample measurement (García-Sellés et al., 2016), the area is defined by the fractures contained by each fracture stratigraphic unit of each of the considered sectors. The parameters measured with this technique are:

- measures of abundance (Dershowitz and Herda, 1992): $P_{20}, P_{21}, P_{22}$ (with fracture aperture available);

- vertical persistence (Petit et al., 1994; Gillespie et al., 2001); and

- FSR and FSI (Narr and Suppe, 1991; Gross, 1993).

\section{Additional Measurements}

Parameters of fracture linear intensity $\mathrm{P}_{10}$ and areal intensity $\mathrm{P}_{21}$ (Dershowitz and Herda, 1992) measured previously from the virtual fracture model are used to extrapolate the intensity from which the volumetric measure of fracture intensity, $\mathrm{P}_{32}$, is calculated. These indirect measurements are calculated with the methodology developed by Wang (2005) and referred to as $\mathrm{P}_{32} \mathrm{C}_{13}$ for $\mathrm{P}_{10}$ and $\mathrm{P}_{32} \mathrm{C}_{23}$ for $\mathrm{P}_{21}$. Parameters of fracture porosity $\left(\mathrm{P}_{11}, \mathrm{P}_{22}, \mathrm{P}_{33}\right)$ can be calculated when the fracture aperture is measured. 
GARCÍA-SELLÉS ET AL.

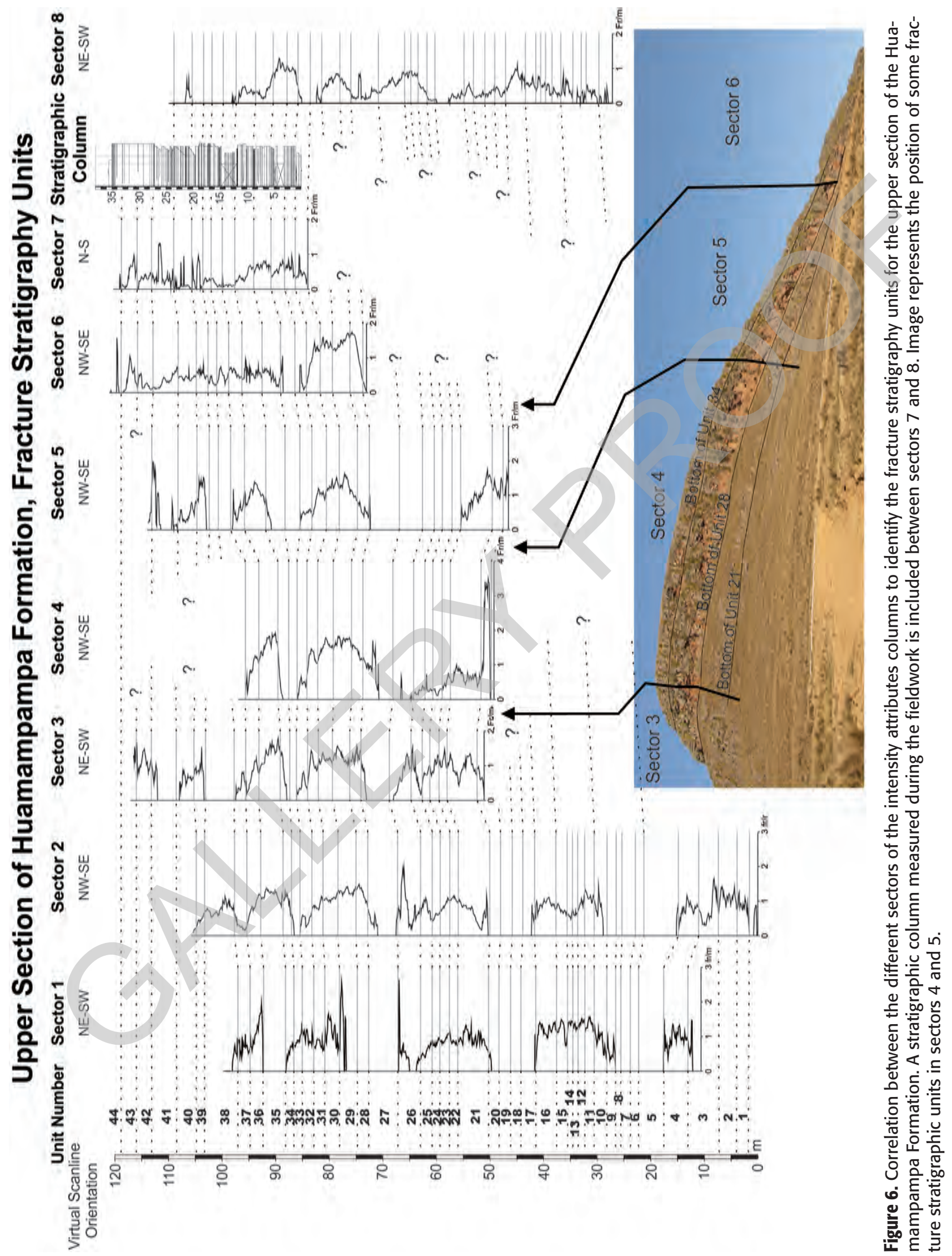




\section{Lower Section of Huamapampa Formation, Fracture Stratigraphy Units}

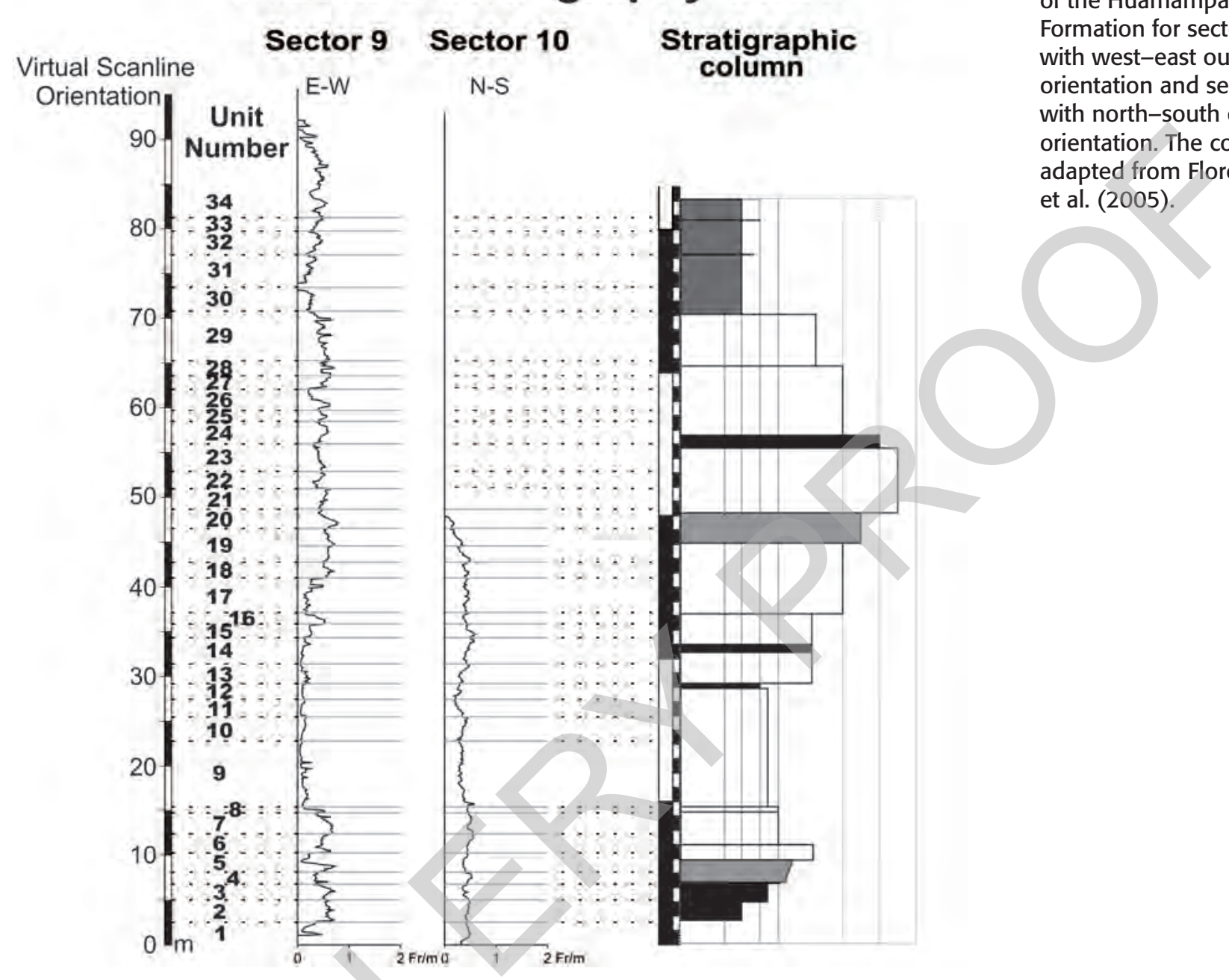

\section{Frequency Distributions}

The large number of fractures $(N=36,279)$ that populate the virtual fracture model obtained from the TLS data set are enough to model fracture size property distributions (Bonnet et al., 2001). However, it is not enough to be analyzed according to fracture stratigraphic units but by fracture sets and sectors. Fracture size properties include the length and height distributions. They are classified by the fracture orientation set for each sector. Fracture spacing data distribution is represented by the frequency distribution from the spacing between fractures of the same fracture orientation set during the virtual scanline measurements. Analyses of the resulting data are compared to a line of best fit in order to obtain correct fit equation lines.
Figure 7. Correlation of the intensity attribute for the lower section of the Huamampampa Formation for sector 9 with west-east outcrop orientation and sector 10 with north-south outcrop orientation. The column is adapted from Florez-Niño et al. (2005)

\section{RESULTS}

Two hundred and fifteen virtual scanlines were measured from the virtual fracture model on the backlimb of the Abra del Condor anticline (Figures 2, 4). Their average length is $77 \mathrm{~m}(253 \mathrm{ft})$ with a maximum of $240 \mathrm{~m}(787 \mathrm{ft})$ and a minimum of $5 \mathrm{~m}(16 \mathrm{ft})$. The measured parameters are represented in Figures 8-24 and Tables 3-6. TLS values have also been used for a new geological map of the Abra del Condor (Figures $2,3,4)$. Vertical cliffs in the outcrop are formed by sandstones of the Huamampampa Formation where the fractures are exposed. They offer an excellent example to use this methodology and TLS acquisition. Nevertheless, fractures developed in shales or thinly bedded units did not develop great fracture 
surfaces. They are neither, therefore, represented in the virtual fracture model nor measured by the virtual scanlines.

\section{Geological Map}

The new geological map presented in this study (Figure 2) contains the most relevant structures in the outcrop that were mapped with the collected TLS and fieldwork data: the map is also based on previous work by Florez-Niño et al. (2005) and Iñigo et al. (2012). The 30-m (98-ft) resolution, ASTER Global Digital Elevation Model, complements the TLS data in creating a topographic base map that validates the geological profiles (Figure 3) and the thickness of the identified sections in the Huamampampa Formation (Table 1).

The ortho-image and topographic information (Figure 4) was useful for the digitization and measurement of small normal faults with displacements below

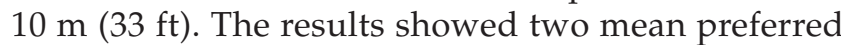
orientations of $345^{\circ} / 90^{\circ}$ and $015^{\circ} / 90^{\circ}$.

\section{Fracture Orientation Set}

Direct observations during the fieldwork and the analysis of the TLS data were used to identify the fracture orientation sets present in the study area. Five fracture orientation sets were identified (Figure 8) from TLS vectorized data and with similar orientations to the outcrop scanline measurements. The two dominant fracture sets, following the nomenclature defined by Florez-Niño et al. (2005) and Iñigo et al. (2012), are sets I and II (blue and red in graphs), which are parallel and perpendicular respectively to the axis of the Abra del Condor anticline. Both fracture sets show a gentle orientation variation along the outcrop according to the changes in the anticline axis orientation. The main anticline axis direction is north-south, but it strikes $15^{\circ} \mathrm{E}$ in sectors 1 to 8 and $10^{\circ} \mathrm{W}$ in sectors 9 and 10 (Figure 9). The stereograms and frequency plots

Table 1. Section thickness of the Huamampampa Formation.

\begin{tabular}{lc}
\hline Huamampampa Sections & Thickness (m) \\
\hline Upper & 120 \\
Middle & 52 \\
Lower & 85 \\
\hline
\end{tabular}

show the predominance in abundance of sets I and II, although results of fracture characterization highly depend on the sector orientation (Figure 8).

With regard to the outcrop orientation and the methodology applied, fracture sets I and III have more reliable measurements in the northwest-southeastand east-west-oriented sectors (Figure 4), whereas fracture sets II and IV have optimal orientations in sectors that are oriented northeast-southwest and north-south. Outcrops favorable to fracture set V are oriented northeast-southwest, northwest-southeast, and north-south.

\section{Outcrop Scanlines}

Six outcrop scanlines were measured normal to the two dominant fracture set strikes for fracture stratigraphic unit number 35 in sector 6 (Figures 4, 6). Four scanlines were normal to fracture set I, and two were normal to fracture set II. The total scanline length was $172 \mathrm{~m}$ (564 ft), measuring 398 fractures. Fracture length was measured in 193 fractures with the following mean values: $4 \mathrm{~m}(13 \mathrm{ft})$ in set I and set $\mathrm{V} ; 2 \mathrm{~m}$

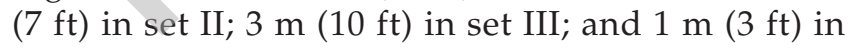
set IV. The maximum lengths were $20 \mathrm{~m}(66 \mathrm{ft})$ and $8 \mathrm{~m}(26 \mathrm{ft})$ for sets I and II, respectively. The fracture characterization for sets I and II is summarized in Table 2.

The mean fracture aperture is $1 \mathrm{~mm}$ (0.04 in.), and this value is used to calculate the abundance measurement of porosity $\mathrm{P}_{11}$ and $\mathrm{P}_{22}$ in the virtual scanlines.

\section{Spacing}

Mean spacing of the dominant fracture sets in the upper section of the Huamampampa Formation

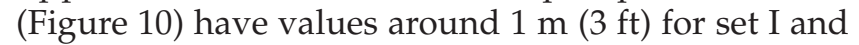
$3 \mathrm{~m}(10 \mathrm{ft})$ for set II. The rest of the fracture sets show mean spacings of $4 \mathrm{~m}(13 \mathrm{ft}), 6 \mathrm{~m}(20 \mathrm{ft})$, and $8 \mathrm{~m}(26 \mathrm{ft})$, respectively. In the lower section of the Huamampampa Formation, the dominant sets present higher mean spacings of $2 \mathrm{~m}(7 \mathrm{ft}), 12 \mathrm{~m}(39 \mathrm{ft})$, and $8 \mathrm{~m}(26 \mathrm{ft})$. The number of fractures in each unit of the virtual fracture model is depicted in Figure 11.

The calculated spacing values are plotted as frequency distributions per each fracture set and sector (Figure 12). Exponential functions are the equation type that best fits these distributions with a mean quadratic error of 0.951 in the range of 0.995 and 0.812 , which is considered a good fit. Function exponents are shown in Table 3. 


\section{Rose Diagrams, Stereonets and Contouring of Poles to Fractures}

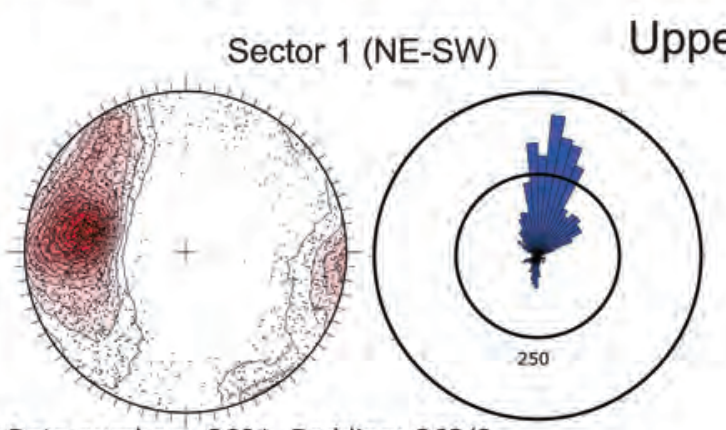

Data number $=2691$ Bedding: $262 / 9$

Min value $=0$ Increment $=0.9$
Section

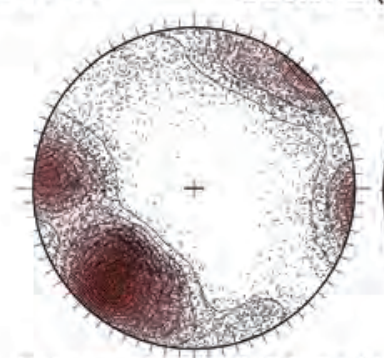

Data number $=12322$ Bedding: $210 / 6$ Min value $=0$ Increment $=0.9$

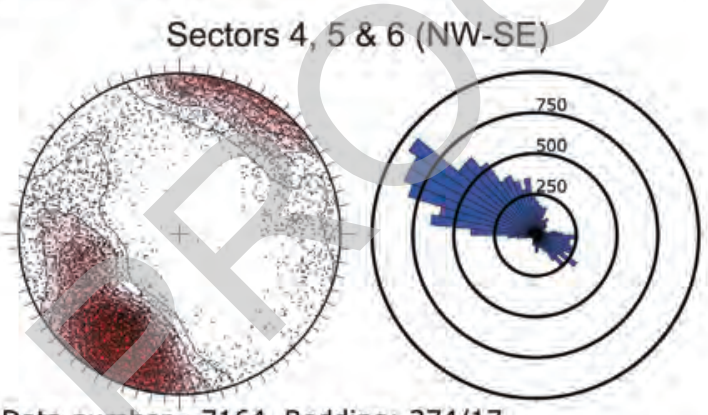

Data number $=7164$ Bedding: $274 / 17$ Min value $=0$ Increment $=0.9$
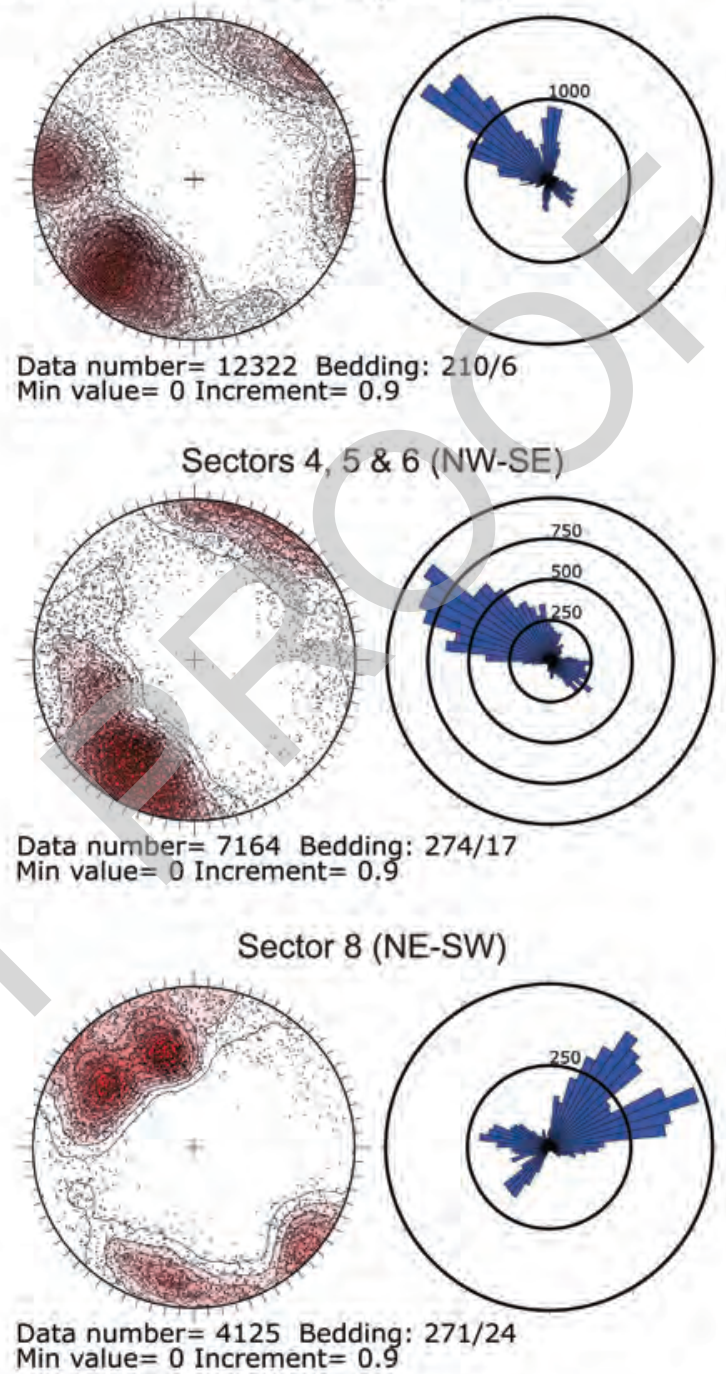

Data number $=1904$ Bedding
Min value $=0$ Increment $=0.9$

7 (N-S)

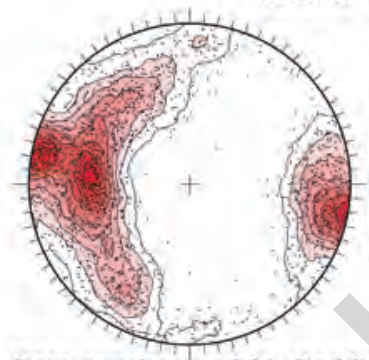

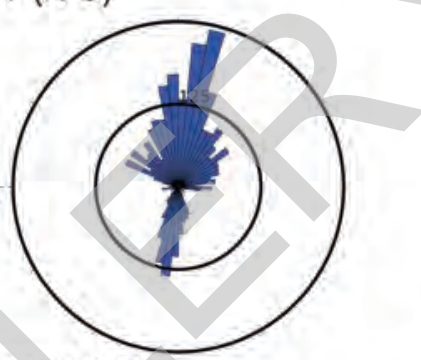

$278 / 19$

9 (E-W)
Lower Section

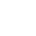

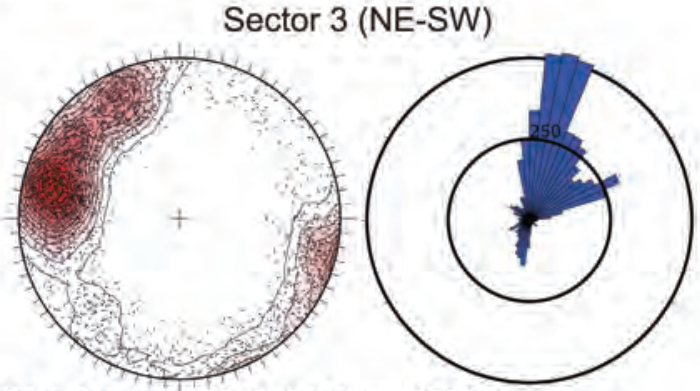

Data number $=3357$ Bedding: $250 / 11$

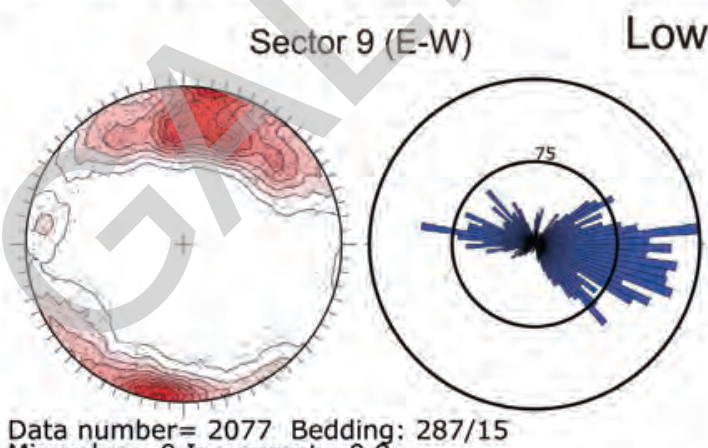

Data number $=2077$ Bedding: $287 / 15$ Min value $=0$ Increment $=0.9$

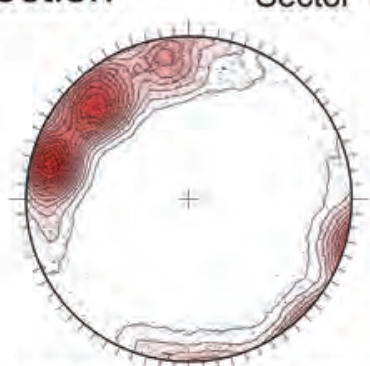

Data number $=2639$ Bedding $269 / 14$ Min value $=0$ Increment $=0.9$

Figure 8. Stereonets and contouring of fracture poles (and Rose diagrams), with circular fracture strike frequency by sectors. Rose diagrams show azimuthal frequencies with the quantity of data for each interval. Contouring of total poles to reconstructed fractures and frequency distribution with reference to bedding for each sector and for the total number of fractures. The intensity of the stereonet data shows the predominance of the fracture sets I and II. Also is visible the dependence of the results with the outcrop orientation. 


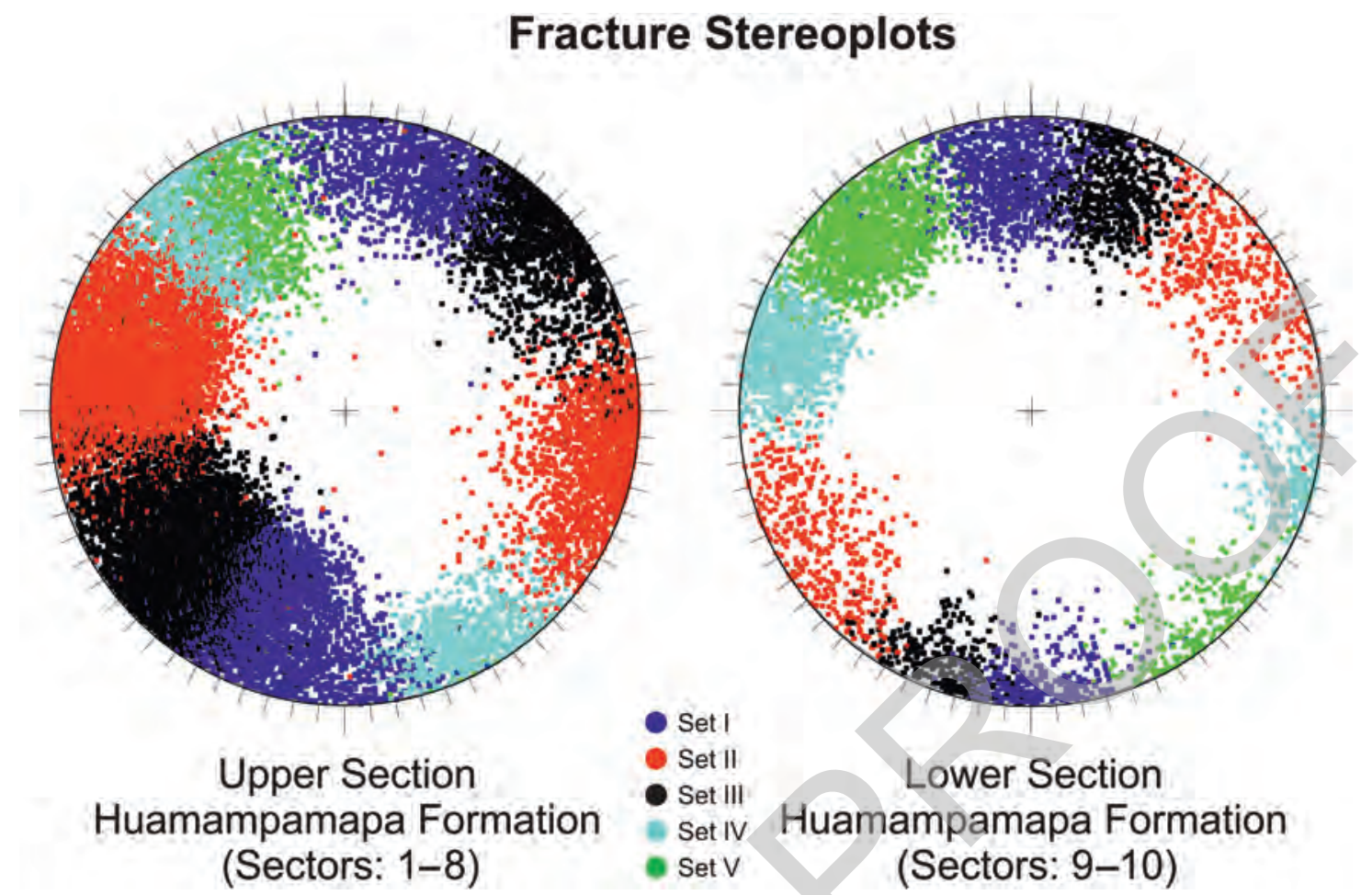

Figure 9. Stereoplots of the reconstructed fractures for upper and lower sections of the Huamampampa Formation. Differences of the same fracture set orientation between the sections of the Huamampampa Formation are due to the variations in the orientation of the fold axis.

Table 2. Main fracture characteristic from the outcrop scanlines measured in sector 6 . Fracture data set 389 . Mean bedding orientation: $273^{\circ} / 26^{\circ}$ in this sector.

\begin{tabular}{cccccc}
\hline Fracture Set & Orientation & Aperture $(\mathbf{m m})$ & $\mathbf{P}_{\mathbf{1 0}}(\mathbf{f r} . \mathbf{m})$ & Spacing $(\mathbf{m})$ & Coefficient Variation \\
\hline I & $005 / 85$ & 1 & 2.6 & 0.38 & 0.98 \\
II & $250 / 85$ & & & & \\
\hline
\end{tabular}

The relation between the fracture stratigraphic unit thickness with the median fracture spacing or FSR per fracture set and sector are plotted in Figure 13. This graph shows a high dispersion for each fracture set indicating that there is not a statistically significant correlation between thickness and spacing. In the same way, FSI shows a weak relation between unit thickness and spacing.

The coefficient of variation quantifies the fracture spacing regularity $\mathrm{Cv}=\sigma / \mu$ where $\sigma$ is the standard deviation of the population spacing and $\mu$ is the arithmetic mean (Gillespie et al., 1999). For random arrangements, the expected value is 1 and for totally regular spacing the value is 0 . Coefficients of variation calculated in the study area are distributed between 0.5 and 2 (Figure 14). The mean value coefficient is located around 1.5. This measurement means that the spacing in the backlimb of the Abra del Condor anticline presents some degree of clustering.

\section{Fracture Size}

Fracture size parameters are represented by fracture height and length. Fractures exposed in the Abra del Condor cliff offer excellent measurements of their heights, as they are totally exposed. However, their censored lengths are impossible to determine due to the rock's perpendicular exposure orientation to the outcrop. In contrast, outcrop scanlines measured at the top of the outcrops do better characterize length than censored fracture heights. 
Fractures Mean Spacing
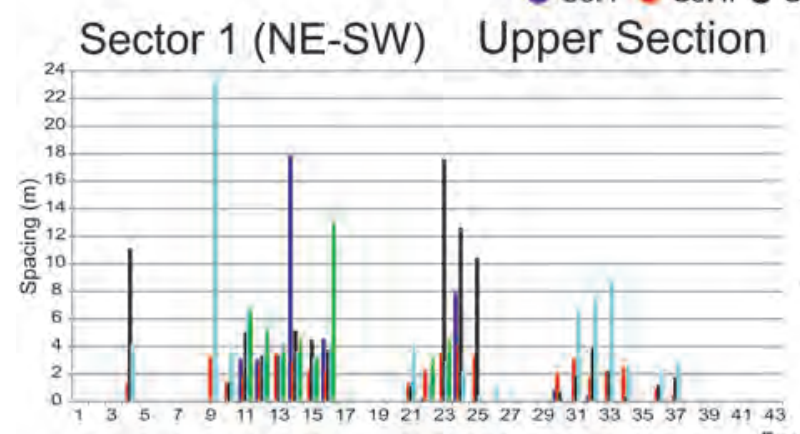

Set III $=$ Set IV a Set V
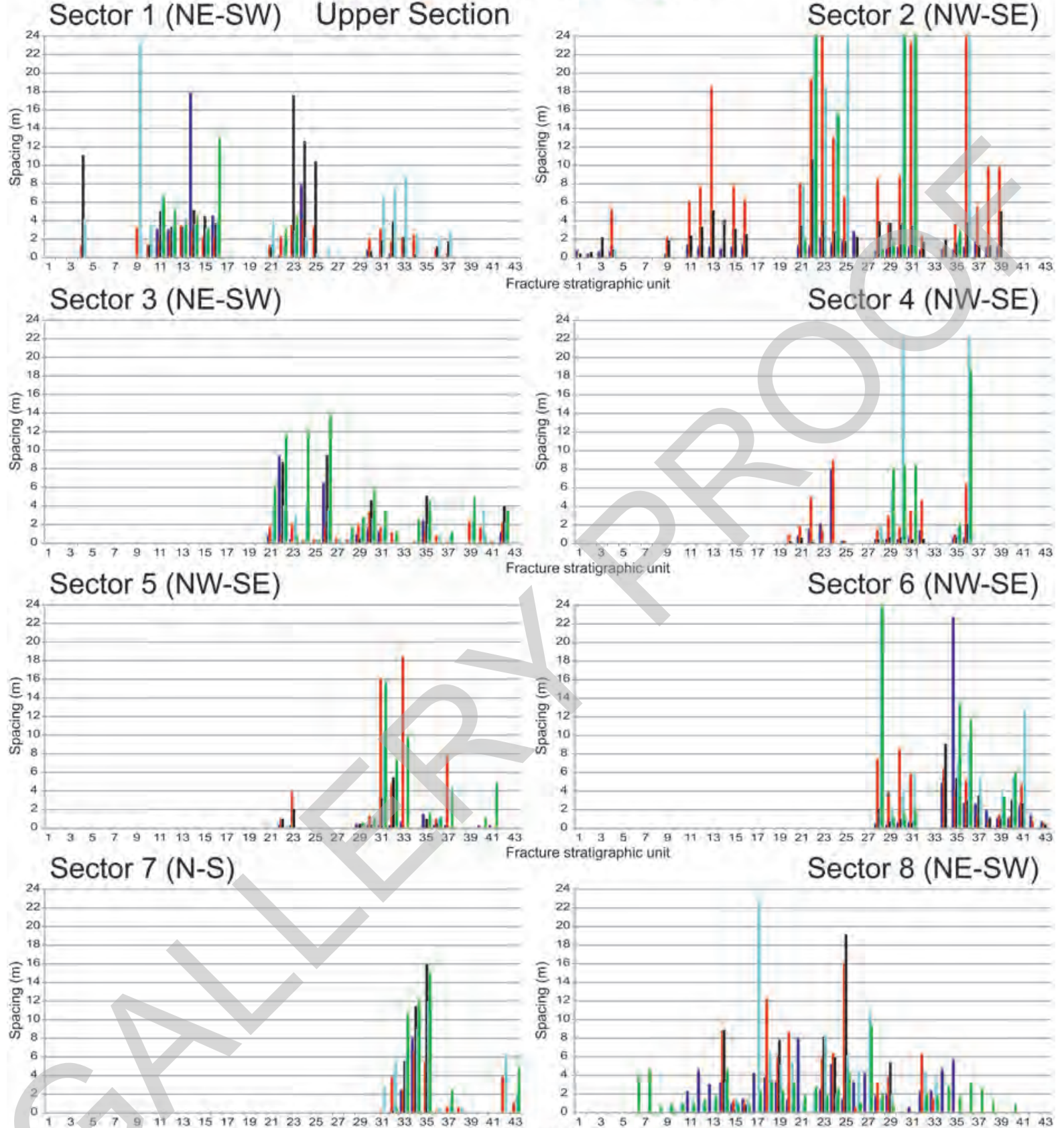

tratigraphic unit

Sector 8 (NE-SW)
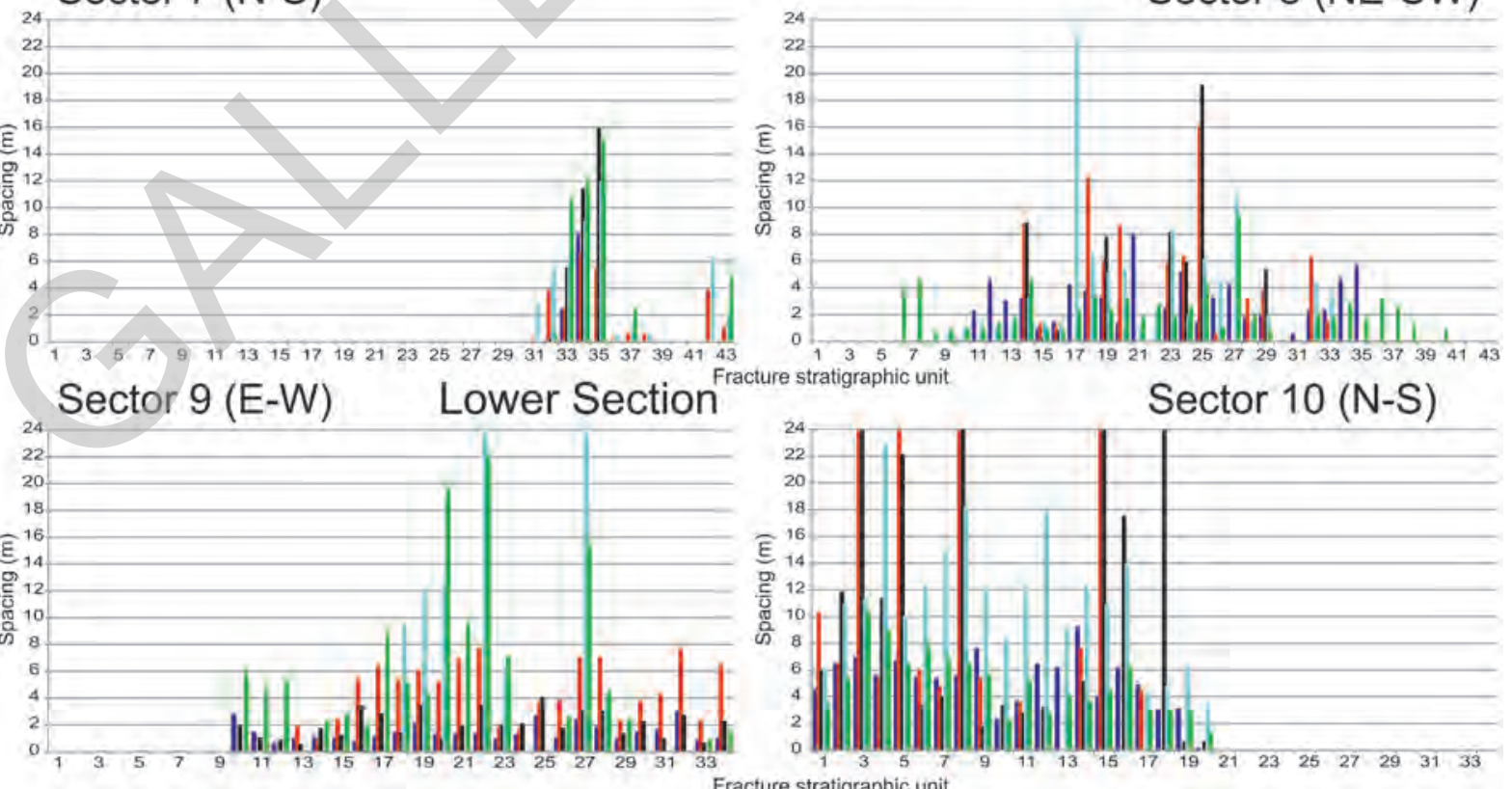

Figure 10. Fractures Mean Spacing. Mean space between fractures of the same fracture set measured perpendicular to the fracture surface for each fracture stratigraphic unit and sector. 
Virtual Scanlines, Number of Fractures - Set I - Set II - Set III \& Set IV • Set V
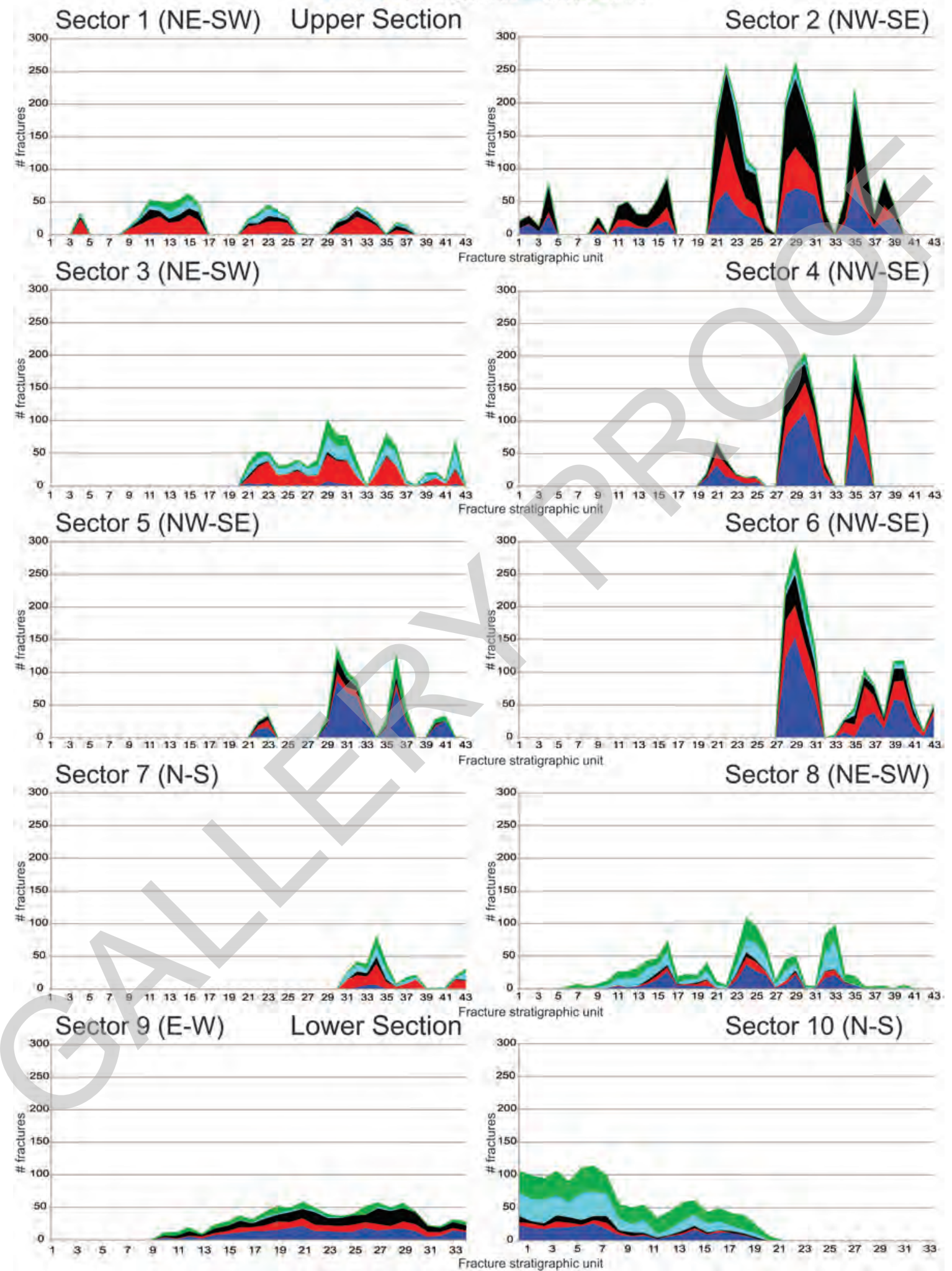

Figure 11. Number of Fractures. Number of fractures measured in each sector and in each fracture stratigraphic unit by each virtual scanline. 


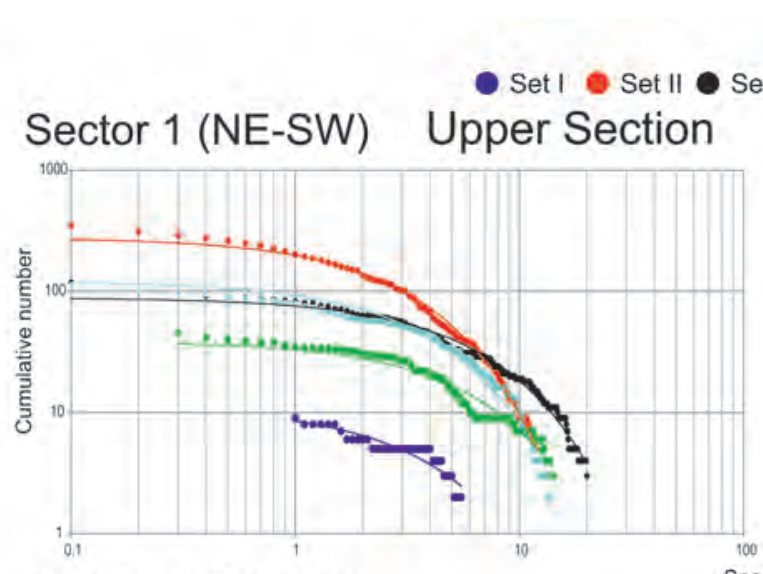

Fracture Spacing Distribution Sector 1 (NE-SW) Upper Section

Sector 3 (NE-SW) Set III S Set IV o Set V
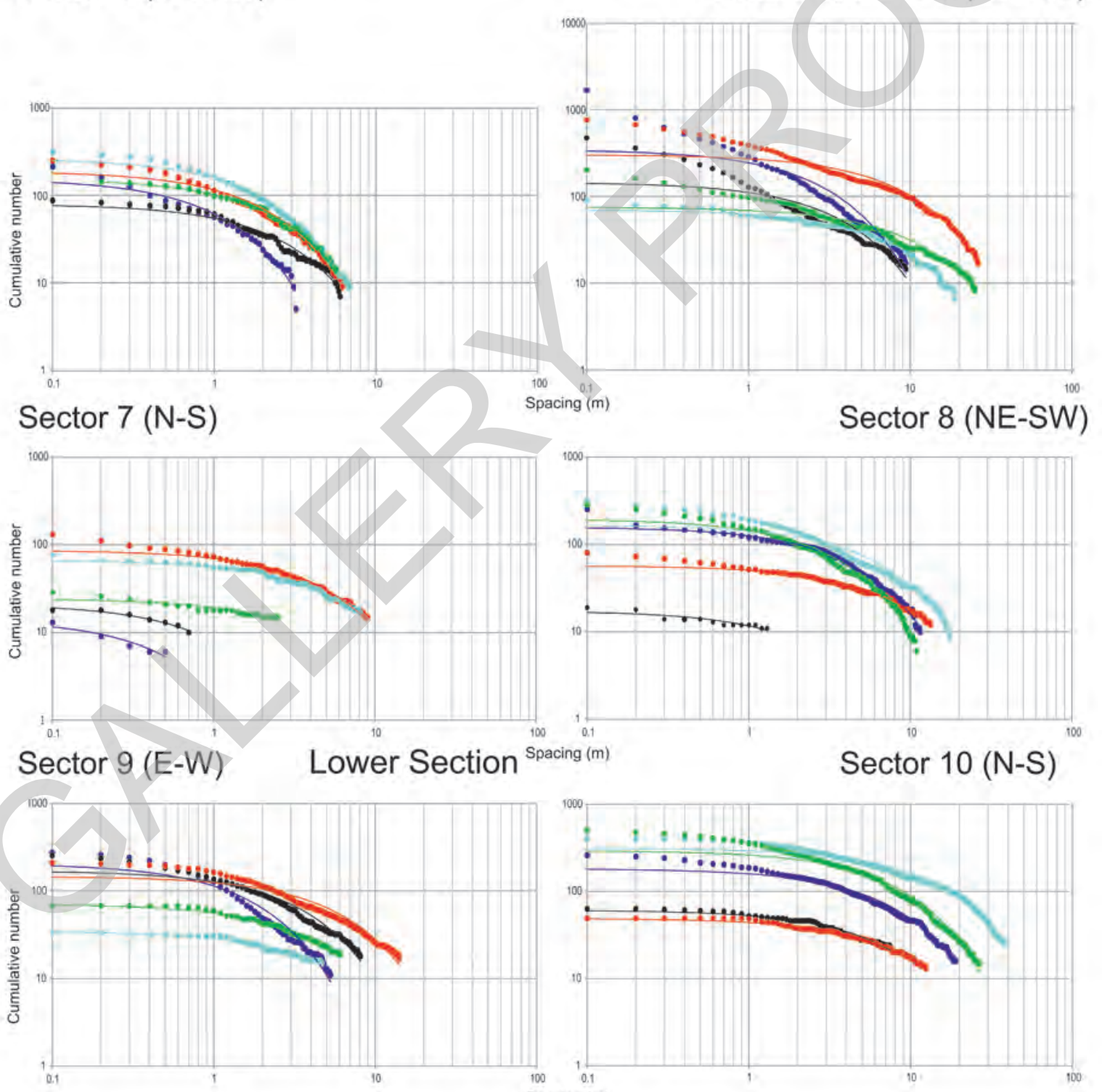

Spacing (m)

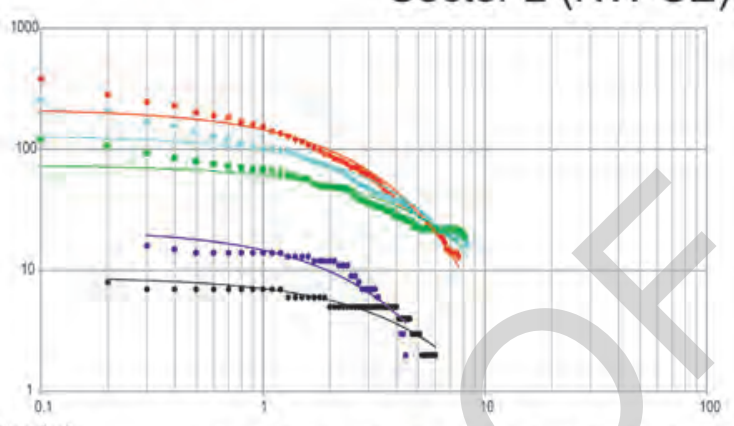

Sectors 4,5 and 6 (NW-SE)

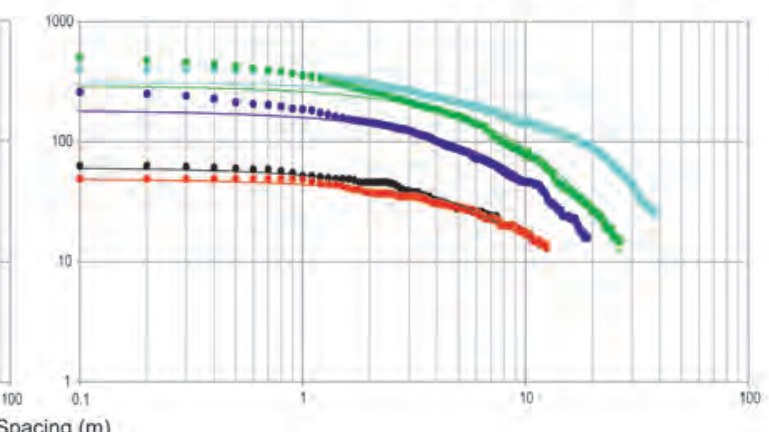

Figure 12. Fracture Spacing Distribution. Cumulative plot of fracture spacing distribution by sectors and orientation of fracture sets. Better fit by an exponential equation; for exponents, see Table 3. 
Table 3. Fit exponential $b$ value from the frequency distribution for spacing measurements in virtual scanlines.

\begin{tabular}{ccccccccc}
\hline Fracture Set & Sector 1 & Sector 2 & Sector 3 & Sectors 4, 5, and 6 & Sector 7 & Sector 8 & Sector 9 & Sector 10 \\
\hline I & 0.27 & 0.4 & 0.91 & 0.34 & 1.95 & 0.23 & 0.58 & 0.13 \\
II & 0.33 & 0.39 & 0.49 & 0.1 & 0.2 & 0.11 & 0.16 & 0.1 \\
III & 0.15 & 0.22 & 0.37 & 0.1 & 0.99 & 0.39 & 0.29 & 0.14 \\
IV & 0.27 & 0.27 & 0.51 & 0.11 & 0.17 & 0.16 & 0.18 & 0.06 \\
V & 0.17 & 0.19 & 0.42 & 0.08 & 0.23 & 0.3 & 0.22 & 0.12 \\
\hline
\end{tabular}

Set I- Set II - Set III $=$ Set IV $=$ SetV

Sector 1 (NE-SW) Upper Section

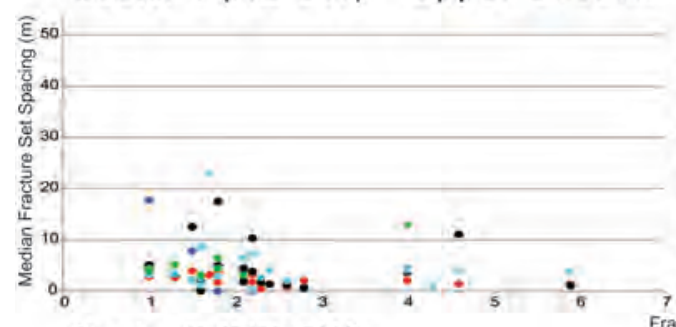

Sector 3 (NE-SW)

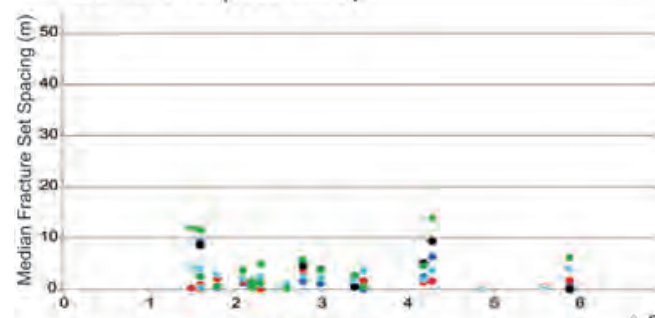

Sector 5 (NW-SE)

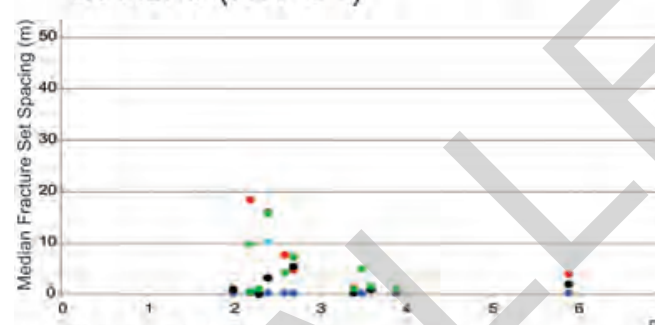

Sector 7 (N-S)
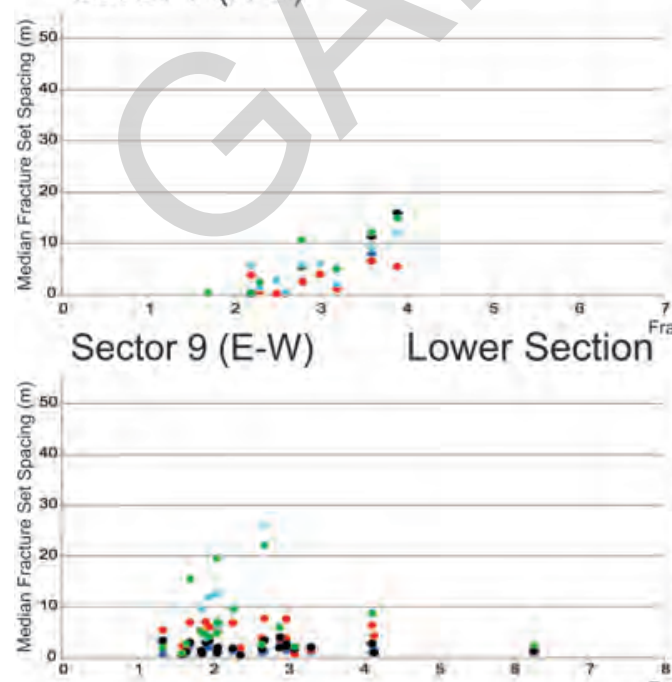

Fracture Spacing Ratio
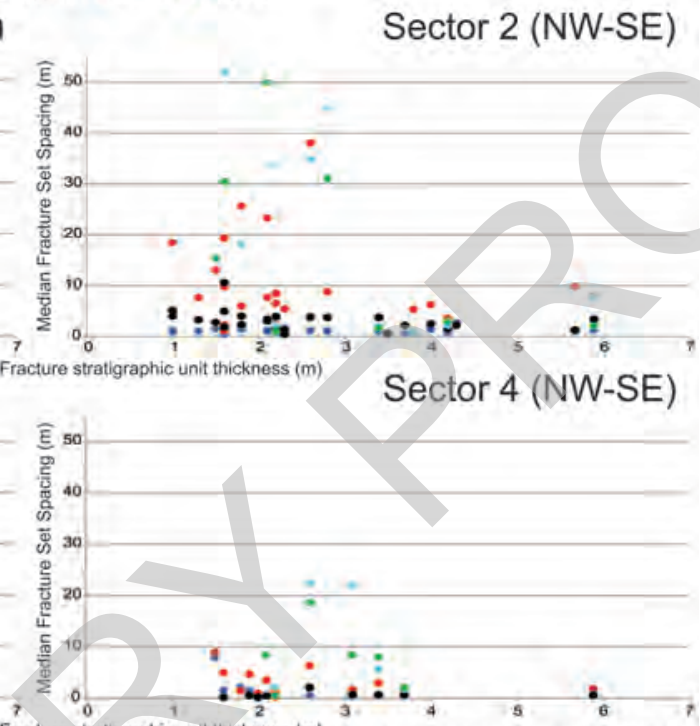

Sector 6 (NW-SE)

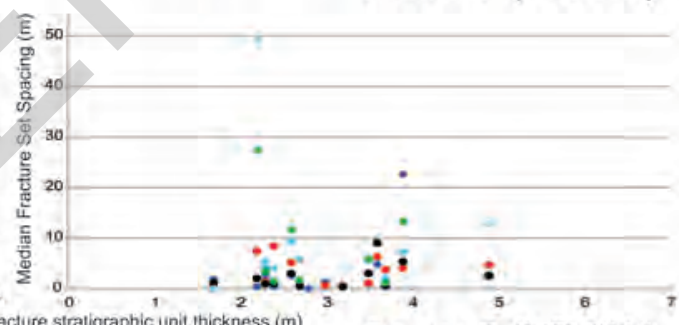

Sector 8 (NE-SW)
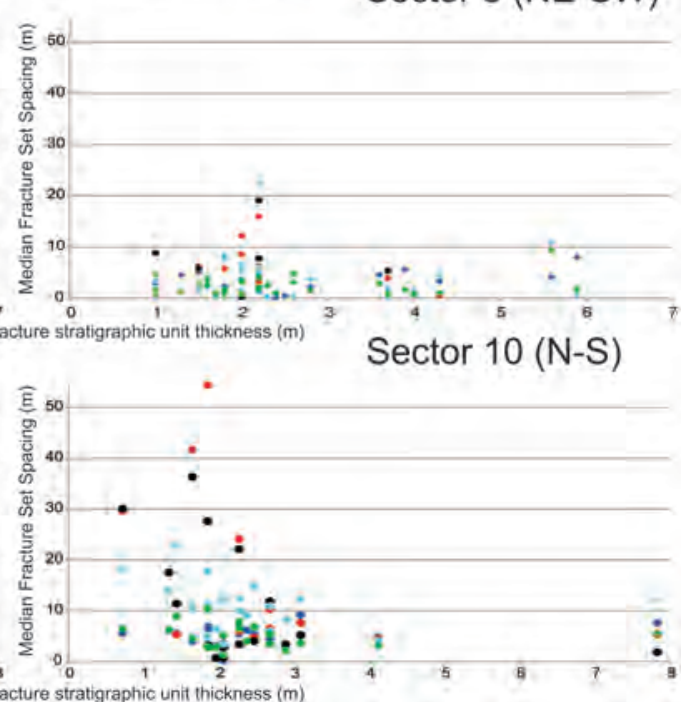

Figure 13. Fracture Spacing Ratio. Ratio between the fracture stratigraphic unit thickness per median fracture set spacing (Gross, 1993). The correlation is considered low. 


\section{Spacing, Coefficient of Variation}

\section{Set I - Set II - Set III I Set IV • Set V}
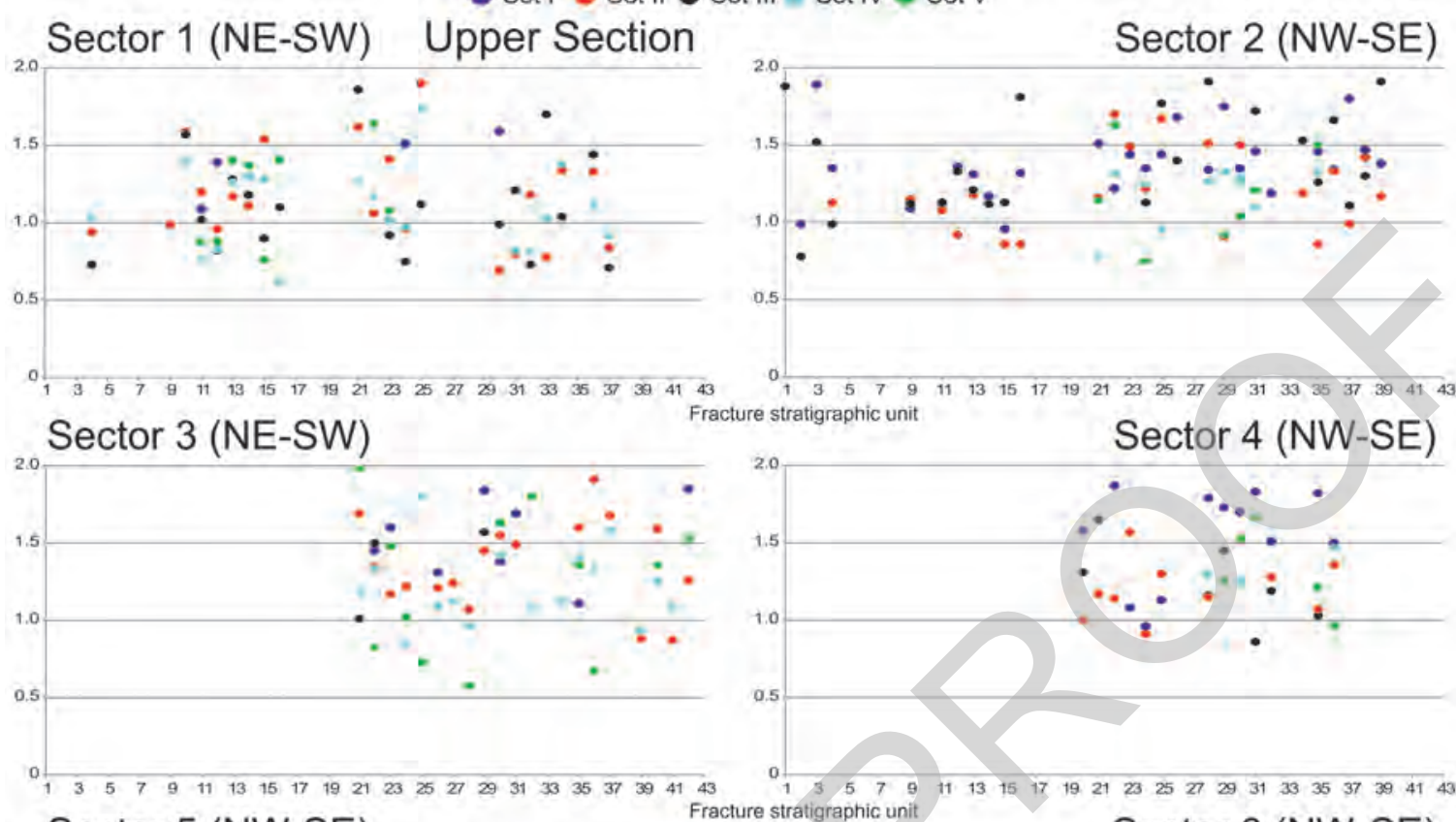

e stratigraphic unit
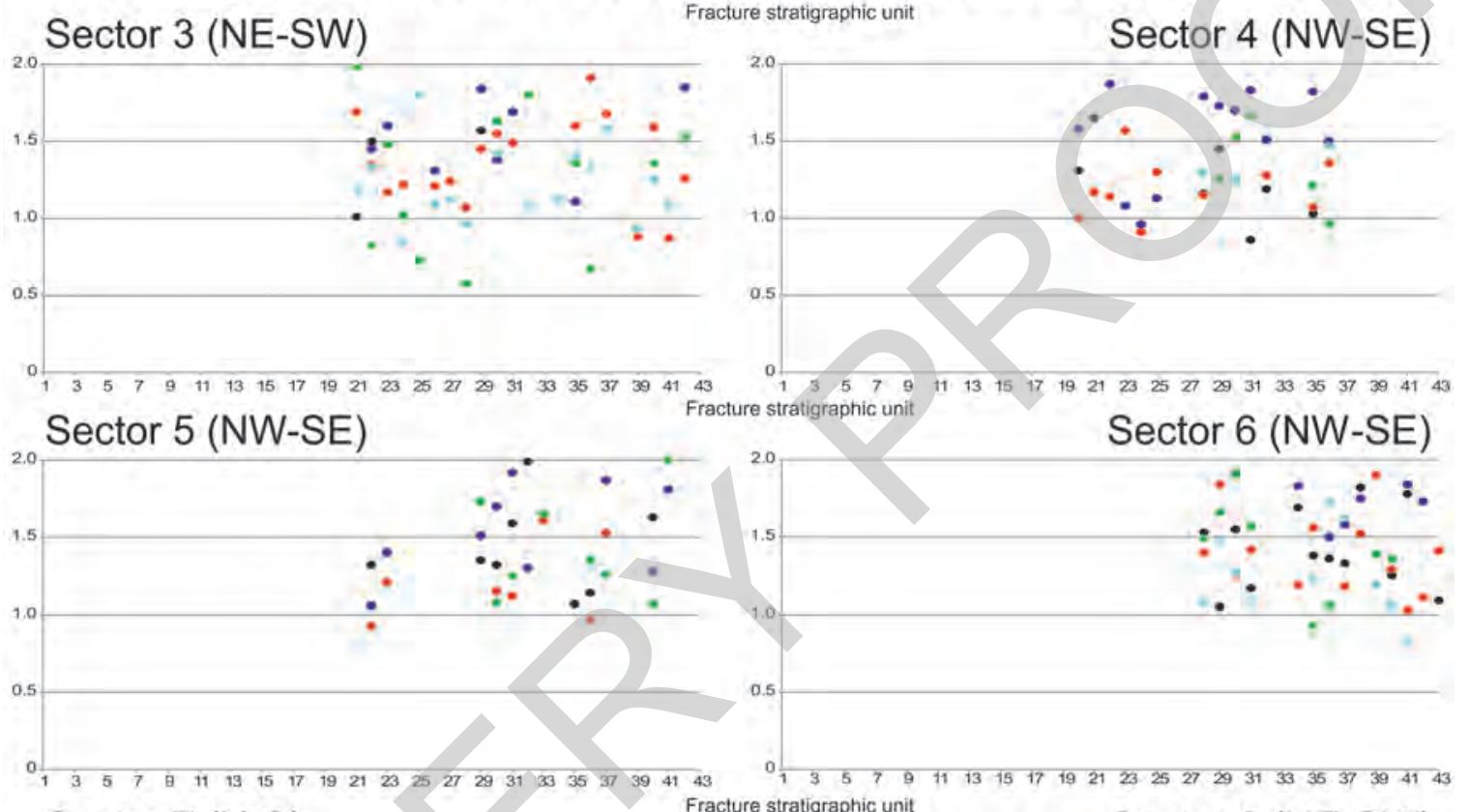

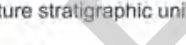

Sector 6 (NW-SE)
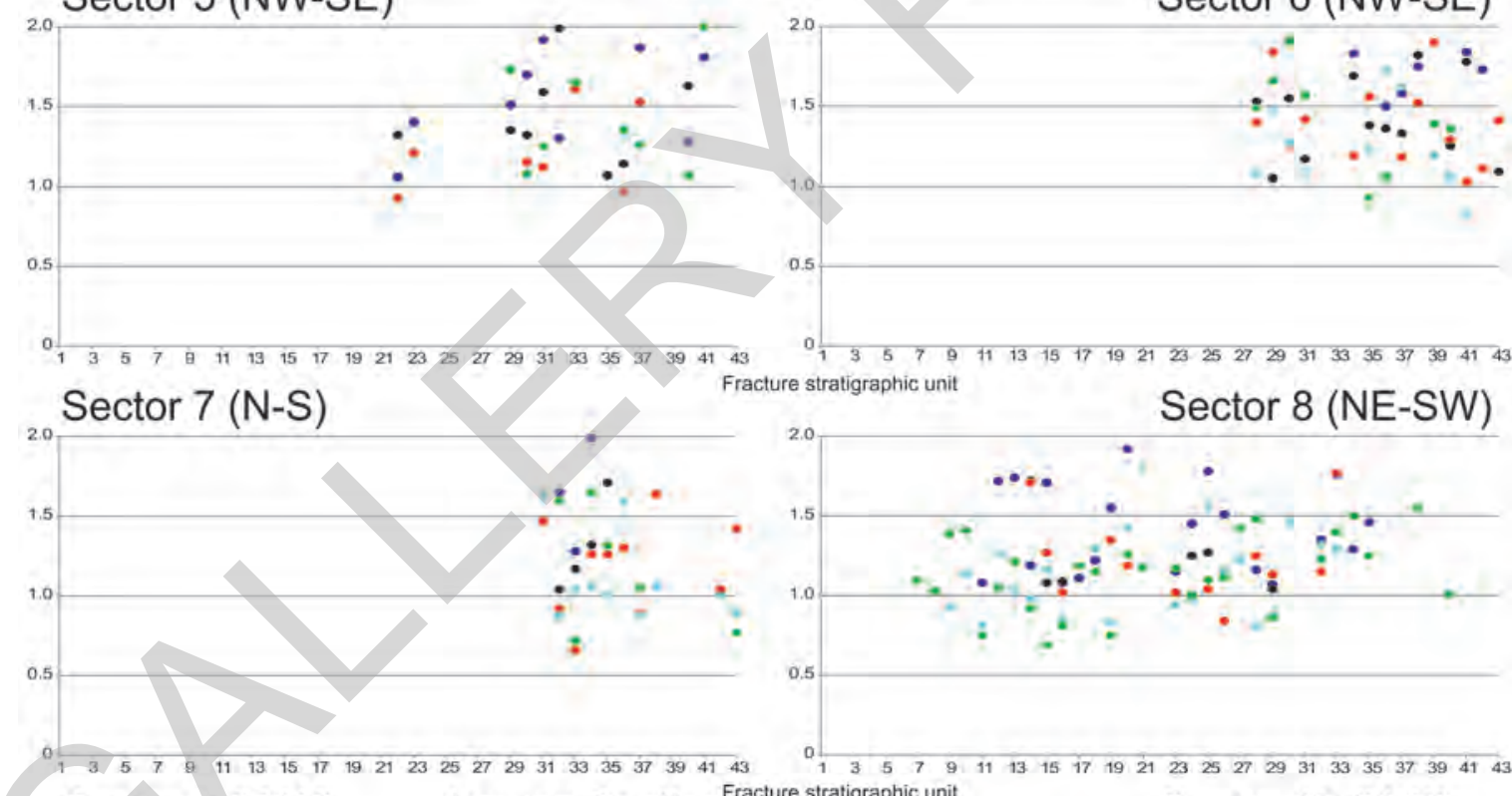
Fracture stratigraphic unit

Sector 8 (NE-SW)

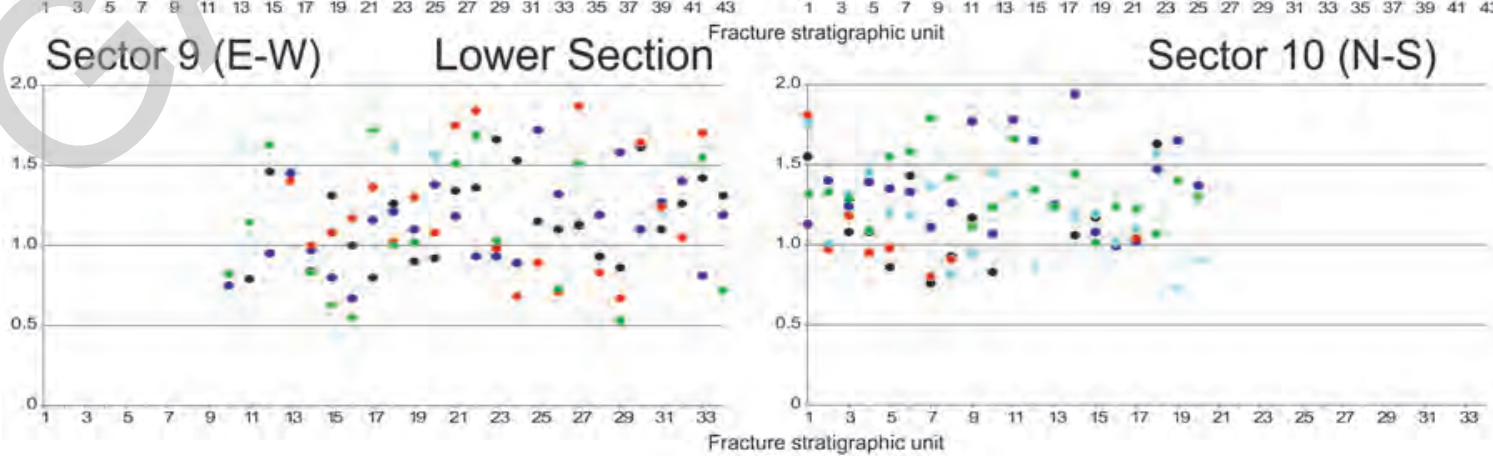

Figure 14. Spacing, Coefficient of Variation. Level of fracture clustering (Gillespie et al., 1999). In general terms, fracture spacing is considered with some degree of clustering. 
Height The mean fracture height for each sector is shown in Figure 15, being mainly below $2 \mathrm{~m}(7 \mathrm{ft})$, but in rare cases, the height may reach $3 \mathrm{~m}(10 \mathrm{ft})$ in sectors of the upper section of the Huamampampa Formation and sector 10 (oriented north-south) of the lower section of the Huamampampa Formation. In contrast, in sector 9 (oriented east-west), most fracture heights are below $3 \mathrm{~m}(10 \mathrm{ft})$, but some reach $4 \mathrm{~m}(13 \mathrm{ft})$, whereas fracture set I exceeds $9 \mathrm{~m}(30 \mathrm{ft})$ in a couple of fracture stratigraphic units. In general, there is neither correlation between fracture sets with sector orientation nor with outcrop orientation with the exception of sector 9 (oriented east-west).

In general, fracture mean heights are below fracture stratigraphic unit thicknesses, except in a few cases where the fracture stratigraphic unit thickness is very short (units 13 and 14 of the upper section of the Huamampampa Formation with a thickness of $1 \mathrm{~m}[3 \mathrm{ft}]$ ). Sector 9 of the lower section of the Huamampampa Formation is where the longest fractures occur, and therefore, heights exceed the fracture stratigraphic unit thickness.

Fracture height distribution by sectors gives a better fit with a power-law function (Figure 16). These fits in frequency distribution have been truncated between minimums of $0.1 \mathrm{~m}(0.3 \mathrm{ft})$ and $0.5 \mathrm{~m}(1.6 \mathrm{ft})$ and below $10 \mathrm{~m}(33 \mathrm{ft})$. The exponents of the power-law function are presented in Table 4 . The upper section of the Huamampampa Formation exponents for fracture sets IV and V are similar and stable, at around 2, whereas in fracture set II, the exponents are of the same order but with different tendencies for each sector. Fracture sets I and II show similar values and evolutions along the 8 sectors. The mean fit error is 0.967 .

Length Mean values of fracture lengths (Figure 17) are below 2-2.5 $\mathrm{m}(6.6-8.2 \mathrm{ft})$, although the maximum values reach $3-4.5 \mathrm{~m}(10-14.8 \mathrm{ft})$ in a few cases. Fracture set $I$ has the longest lengths in the northwest-southeast-oriented sector 2 and the eastwest-oriented sector 9 (Figure 4). For the rest of the sectors, fracture sets with the longest fractures vary between set II, IV, and V, independent of sector orientation.

Fracture length measurements are plotted in frequency distributions' graphs, per fracture set and sector (Figure 18). A power-law function gives the best fits to the length values distribution, independent of the fracture set or the sector orientation. The mean quadratic error of the best fits is considered to be good with a mean error of 0.9677 , ranging between 0.8832 and 0.998 . Function exponents are shown in Table 5. The graphs (Figure 18) depict the similarity between fracture sets I and III and the fracture sets II, IV, and V with regard to slope and proximity, especially in sectors with northwest-southeast orientations (sectors 2, 4, 5, and 6) and sectors with orientation north-south and east-west (sectors 7 and 9, respectively).

\section{Vertical Persistence}

Vertical persistence at the backlimb of the Abra del Condor anticline is shown in Figure 19, and the relationship between fracture stratigraphic units thickness and mean height fracture is shown in Figure 15. The general tendency of the vertical persistence is low or very low. In the upper section of the Huamampampa Formation, the fracture height percentage that exceeds the fracture stratigraphy units' boundaries is lower than $10 \%$, although in a few units, it reaches $50 \%$, with the exception of sector 2, where fracture sets I and III exceed the unit boundaries. For the rest of the sectors, fractures are confined within the fracture stratigraphic units. In the lower section of the Huamampampa Formation, the vertical persistence percentage is larger reaching $25 \%$ and, in some cases, 50\% for all fracture sets.

\section{Fracture Abundance}

Density Measurements from the virtual fracture model for the density parameter $\mathrm{P}_{20}$, proposed by Dershowitz and Herda (1992), are depicted in Figure 20. In the upper section of the Huamampampa Formation, the number of fractures per square meter does not exceed 2 in the majority of the cases, and the main values are below $1 \mathrm{fr} . / \mathrm{m}^{2} . \mathrm{P}_{20}$ in fracture sets I and II oscillates around $2 \mathrm{fr} . / \mathrm{m}^{2}$. Fracture set II preserves its abundance density with the exception of sector 5 (oriented northwest-southeast) and sector 8 (oriented northeast-southwest), where the values are down below $0.5 \mathrm{fr} . / \mathrm{m}^{2}$. Fracture abundance density for fracture set I in sectors $1,3,7$, and 8 is irregular and has low values compared to fracture set II. In the rest of sectors, the abundance density values are higher.

In the lower section of the Huamampampa Formation, the abundance density is lower, below $0.5 \mathrm{fr} . / \mathrm{m}^{2}$, but can exceptionally reach values of $1 \mathrm{fr} . / \mathrm{m}^{2}$ or more. Fracture sets IV and V are predominant only in sector 10 where their abundance density is higher.

Intensity Total values of intensity are highly variable in the units of the upper section of the Huamampampa Formation (Figure 21). The analysis shows $2 \mathrm{fr}$. $/ \mathrm{m}$ as the highest value measured in some sectors with northwest-southeast orientation 
Fractures Mean Height
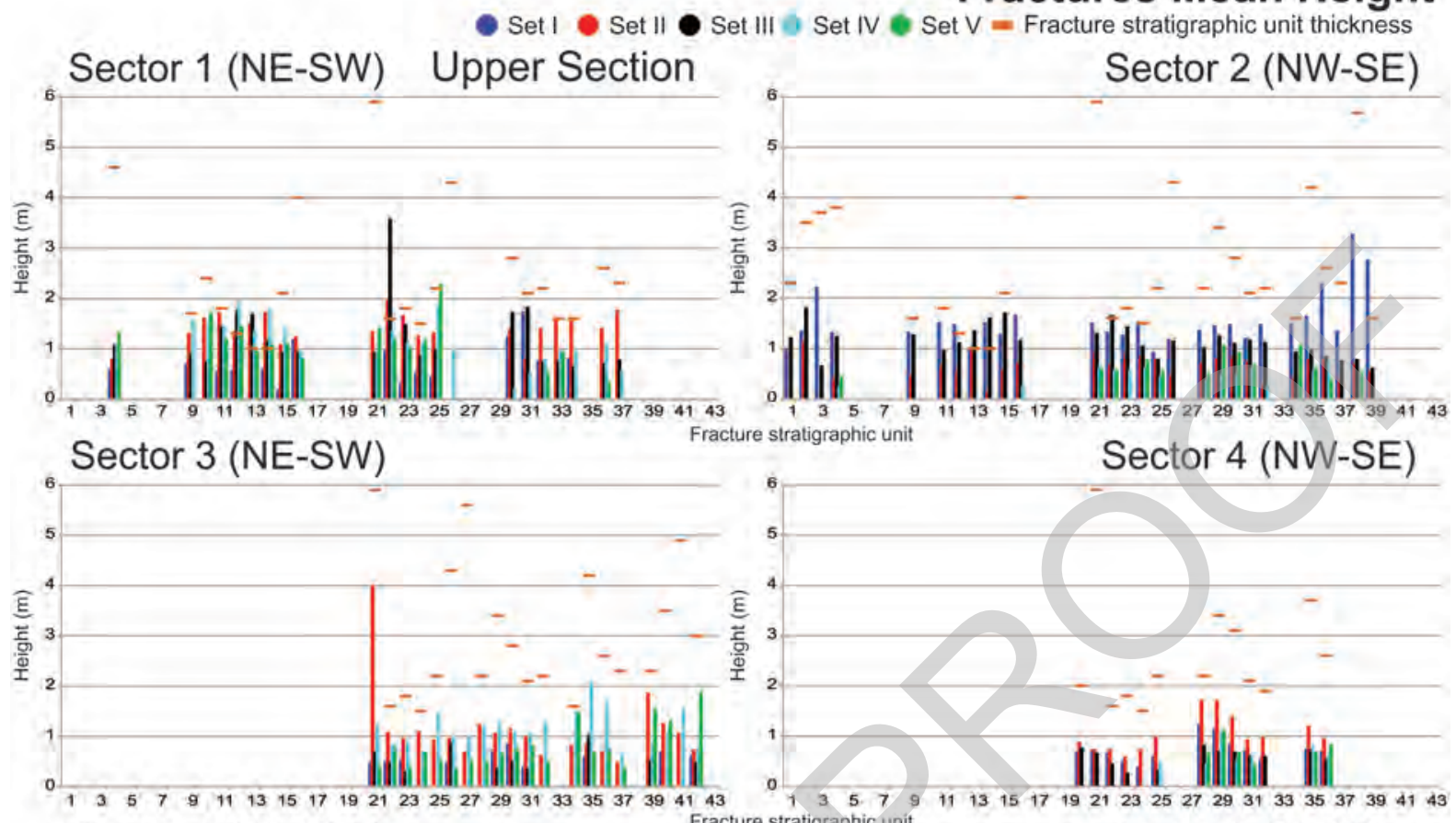

Fistratigraphic unit

Sector 4 (NW-SE)
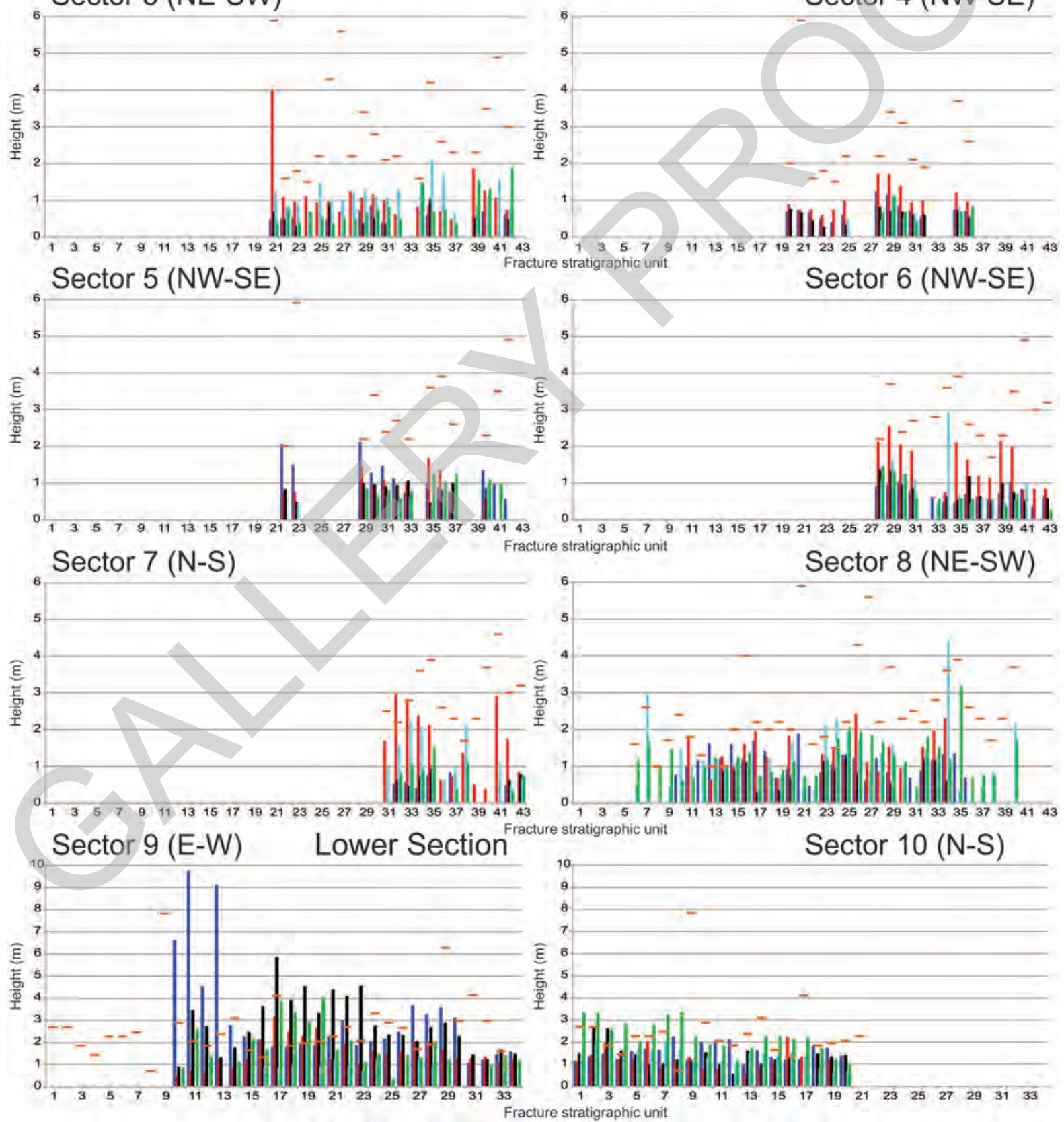

Figure 15. Fracture Mean Height. Mean height of the fractures, intersected by the virtual scanline, included the thickness of each fracture stratigraphic unit in each sector and fracture orientation set. 


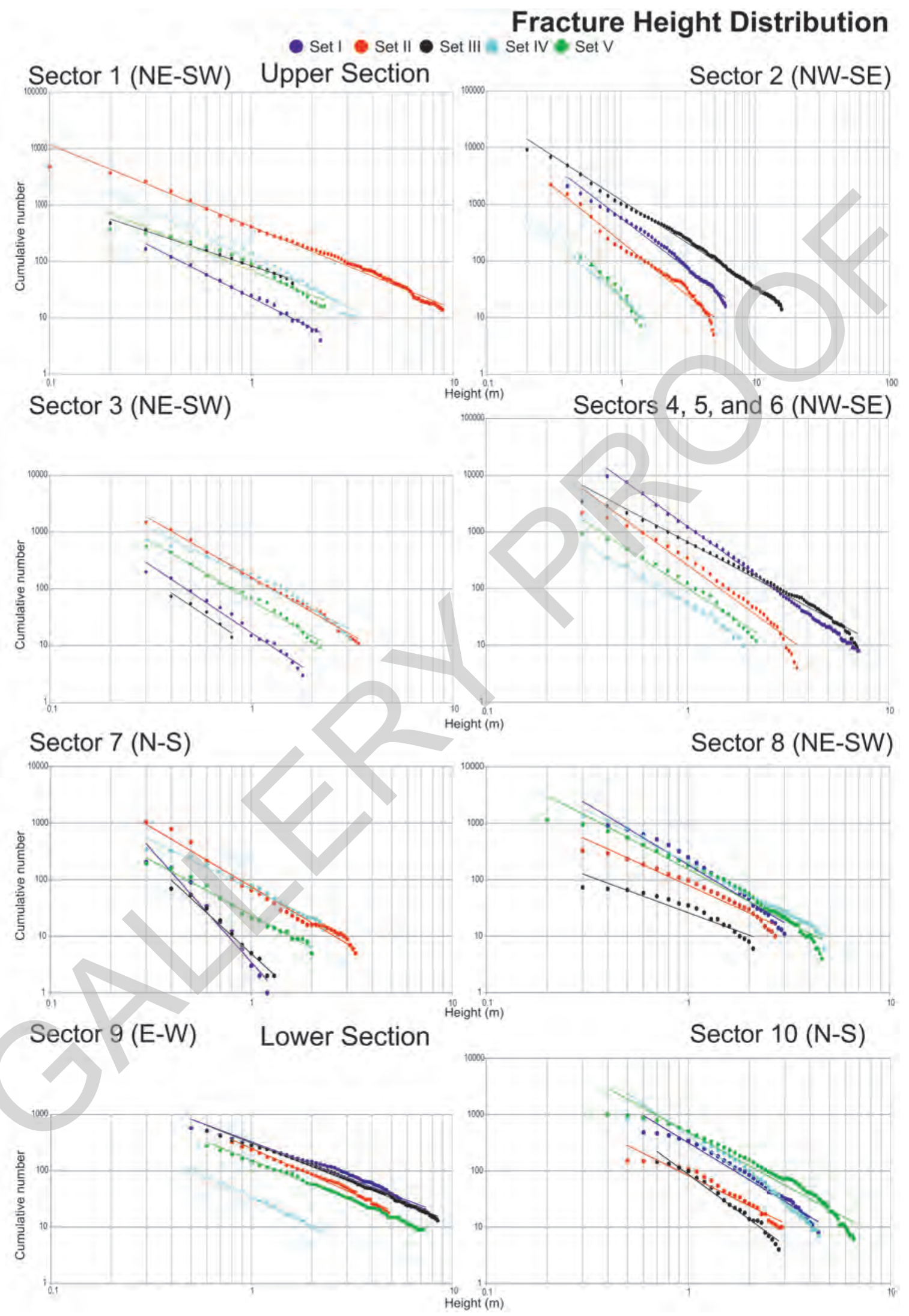

Figure 16. Fracture Height Distribution. Cumulative plot of fracture height distribution by sectors and orientation fracture sets. Better fit by a power-law equation; for exponents see Table 4. 
Table 4. Fit power-law exponent from the frequency distribution for fracture height and sector.

\begin{tabular}{cccccccccc}
\hline & Sector 1 & Sector 2 & Sector 3 & Sector 4 & Sector 5 & Sector 6 & Sector 7 & Sector 8 & Sectors 9 and 10 \\
\hline Mean Fracture $/ \mathrm{m}$ & 0.94 & 0.83 & 0.94 & 1.02 & 0.83 & 0.64 & 0.39 & 0.42 & 0.36 \\
\hline
\end{tabular}

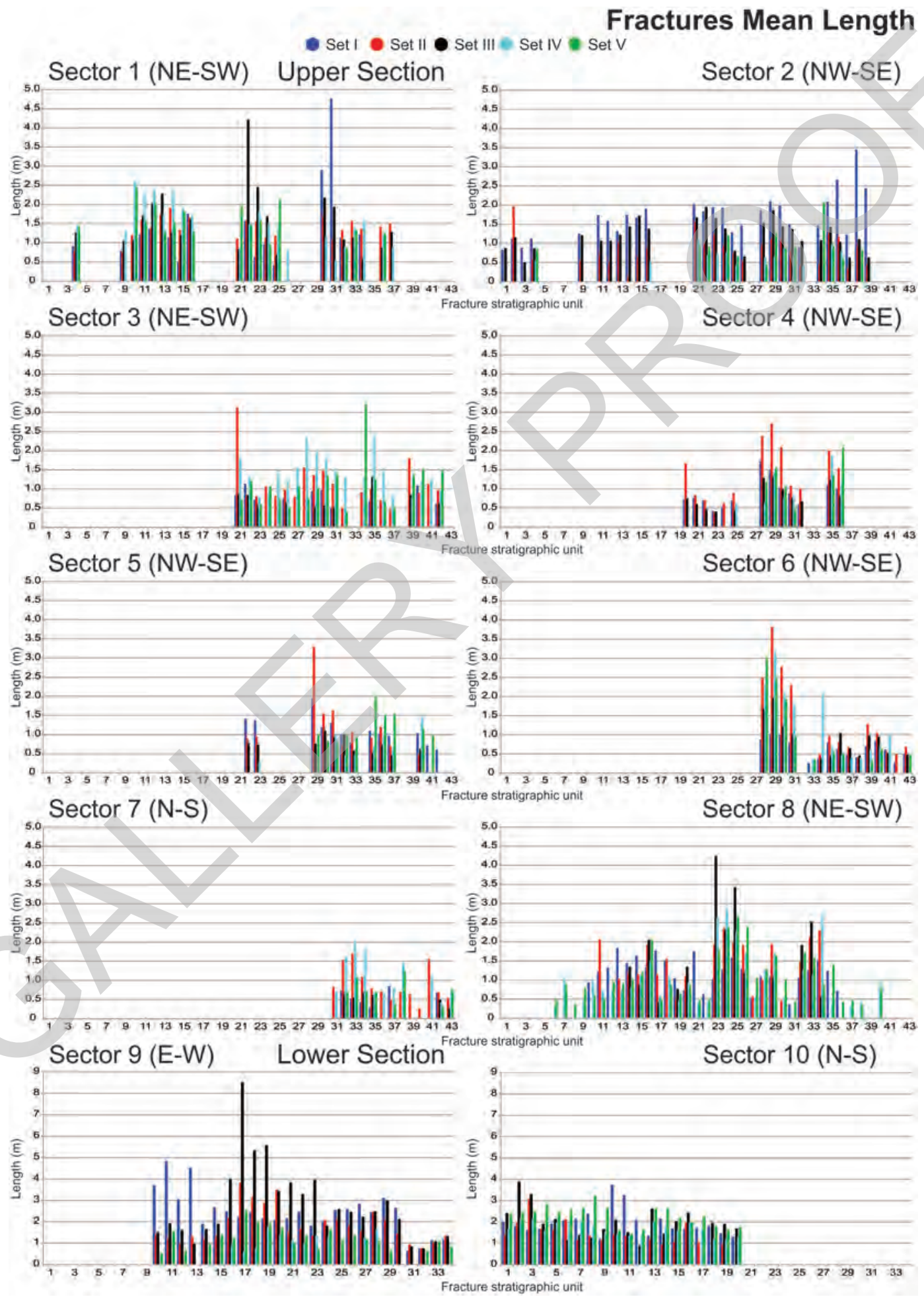

Figure 17. Fractures Mean Length. Mean exposed length of the fractures intersected by the virtual scanline of each fracture stratigraphic unit in each sector and fracture orientation set. 


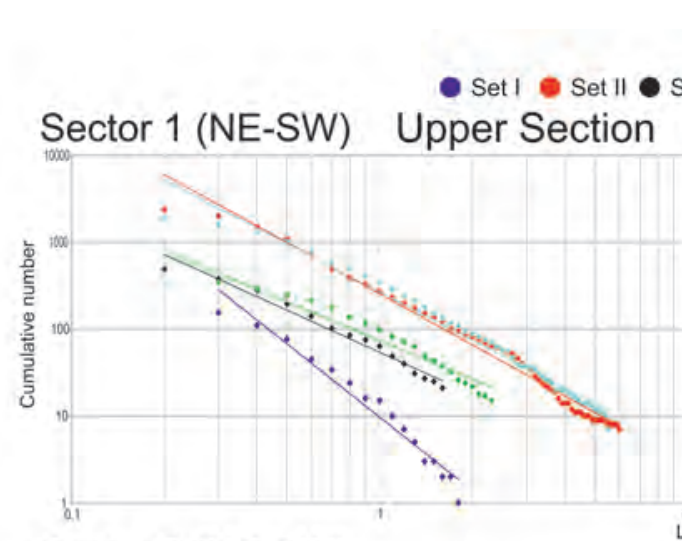

Sector 3 (NE-SW)
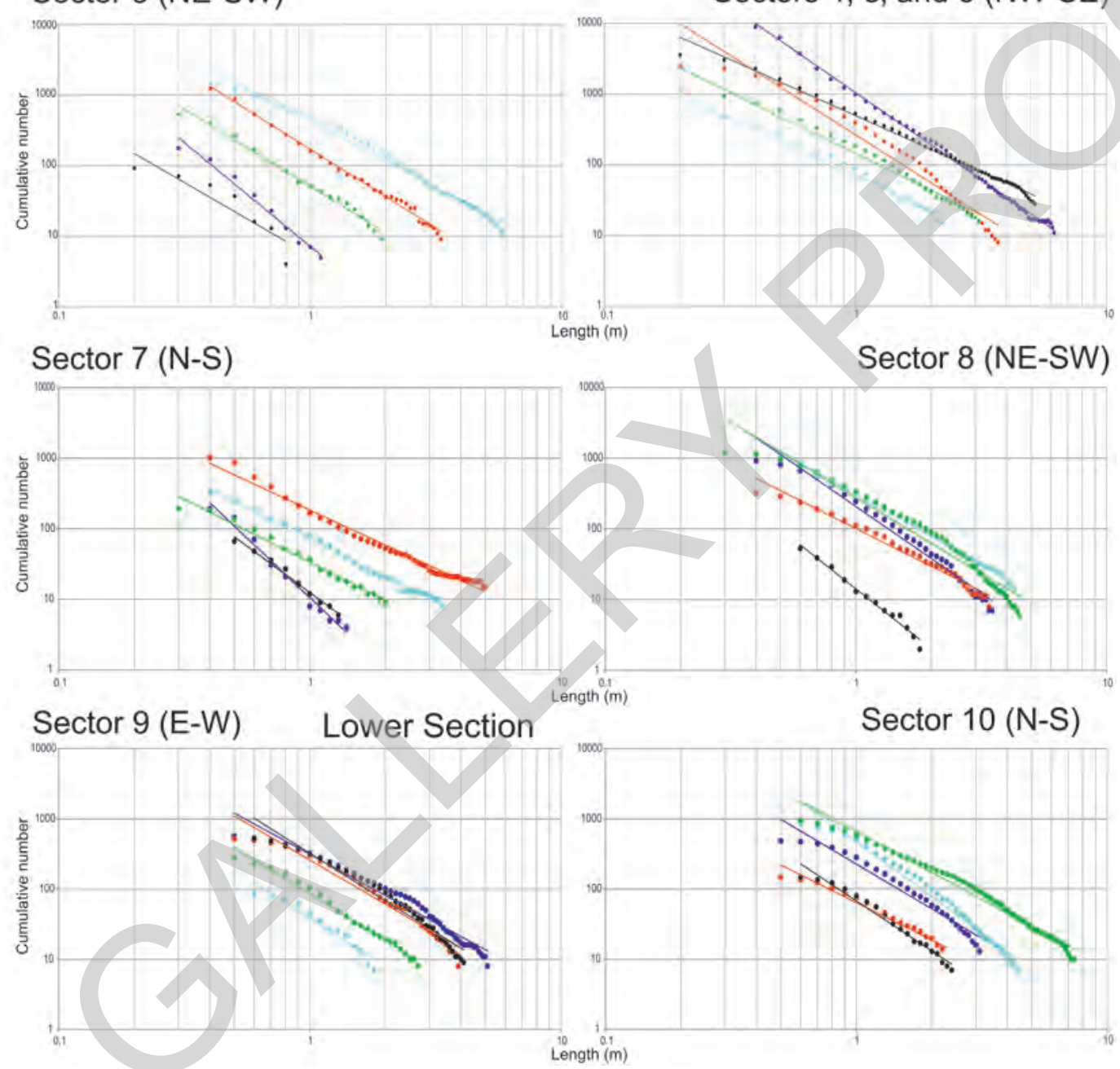

Fracture Length Distribution Sector 2 (NW-SE)

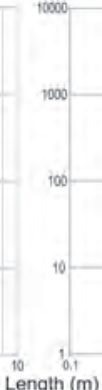

Sectors 4,5 , and 6 (NW-SE)

Sector 8 (NE-SW)
Figure 18. Fracture Length Distribution. Cumulative plot of fracture length distribution by sectors and orientation fracture sets. Better fit by a power-law equation; for exponents see Table 5 .

Table 5. Fit power-law exponent from the frequency distribution for fracture length and sector.

\begin{tabular}{ccccccccc}
\hline Fracture Set & Sector $\mathbf{1}$ & Sector $\mathbf{2}$ & Sector 3 & Sectors 4, 5, and 6 & Sector 7 & Sector 8 & Sector 9 & Sector 10 \\
\hline I & 1.82 & 1.81 & 2.37 & 2.45 & 4 & 2.15 & 1.33 & 2.18 \\
II & 1.45 & 1.92 & 2.04 & 2.24 & 2.11 & 1.61 & 1.57 & 1.77 \\
III & 1.18 & 1.53 & 2.35 & 1.58 & 3.26 & 1.31 & 1.4 & 2.63 \\
IV & 1.74 & 2.06 & 1.79 & 1.62 & 1.71 & 1.85 & 1.63 & 2.46 \\
V & 1.45 & 2.69 & 2.09 & 1.72 & 1.93 & 1.88 & 1.43 & 1.95 \\
\hline
\end{tabular}




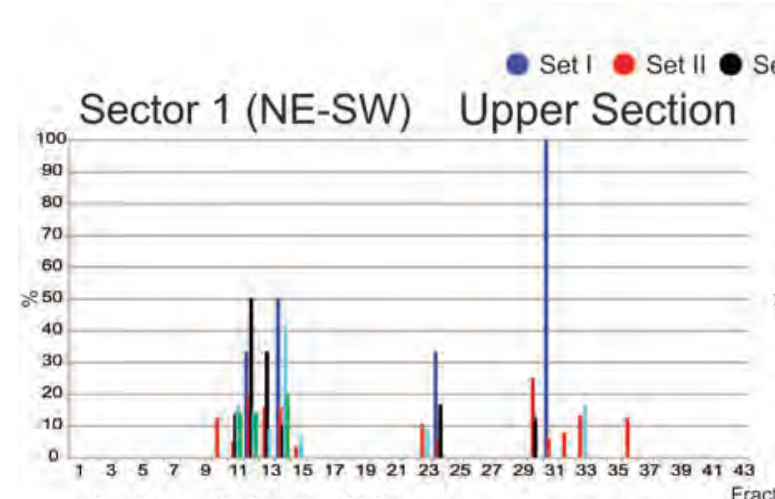

Set III $=$ Set IV e Set V

Vertical Persistence
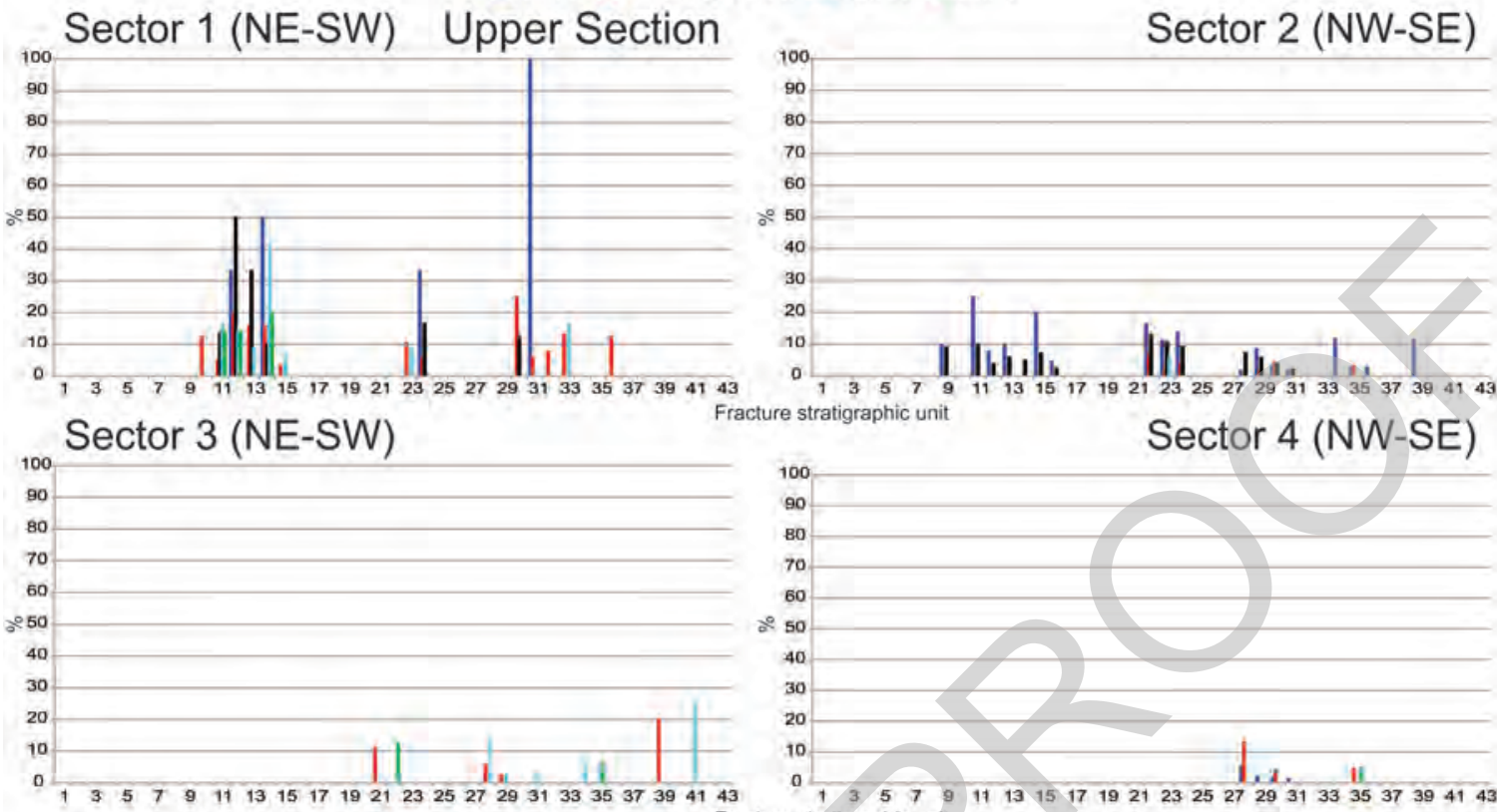
acture stratigraphic unit
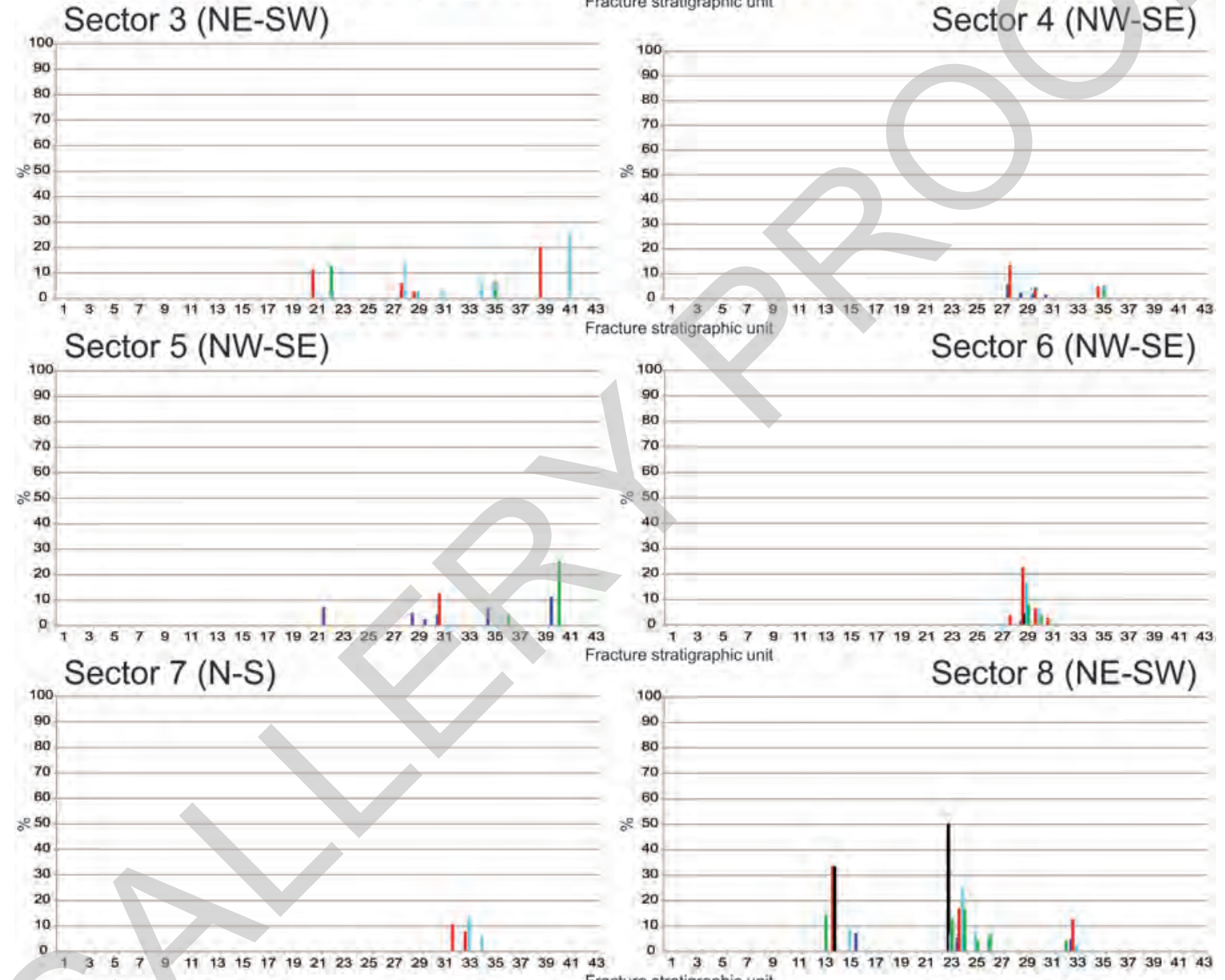

racture stratigraphic unit
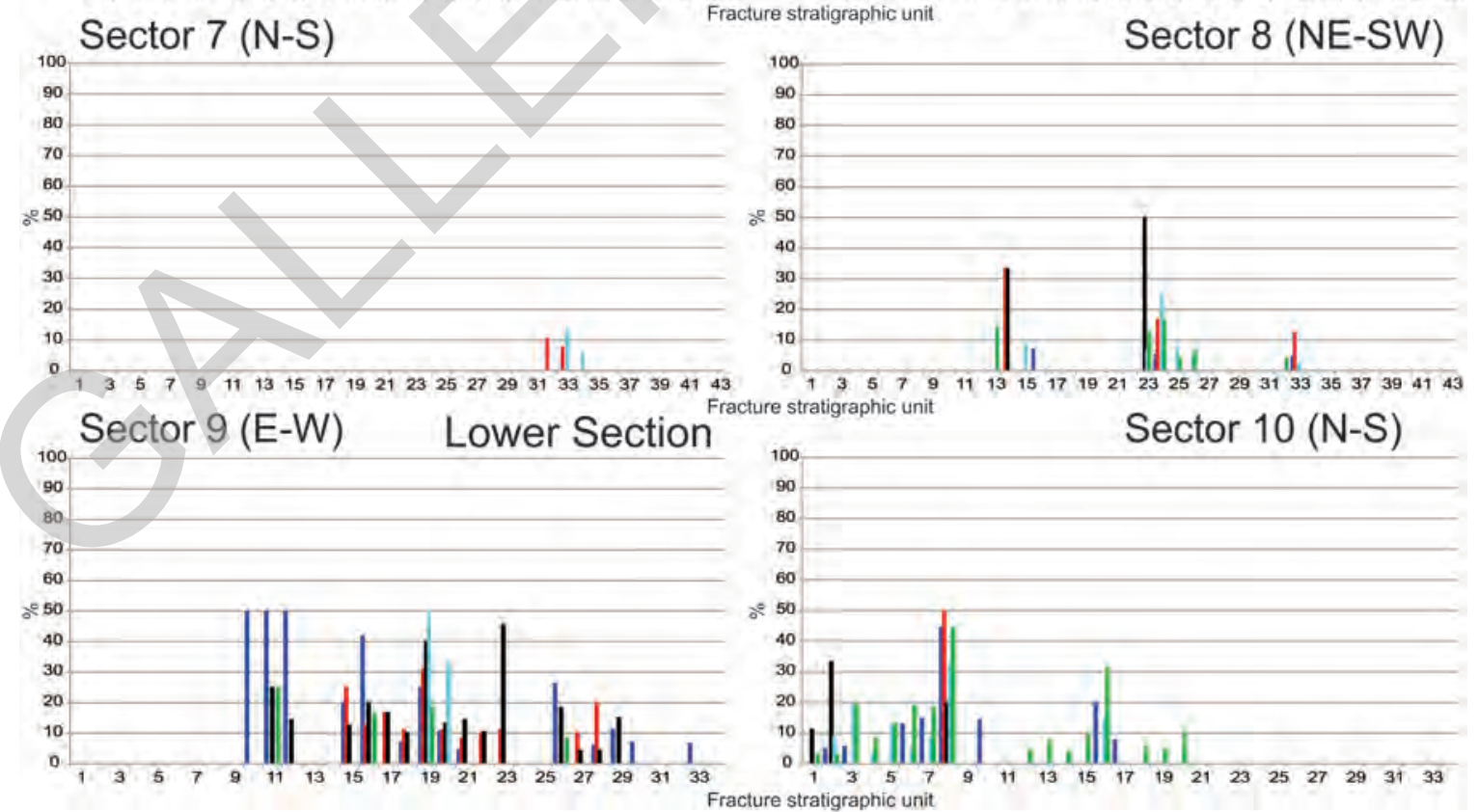

Figure 19. Vertical Persistence. Percentage of fractures that cross the unit boundary by fracture orientation set in each sector and in each fracture stratigraphic unit. 


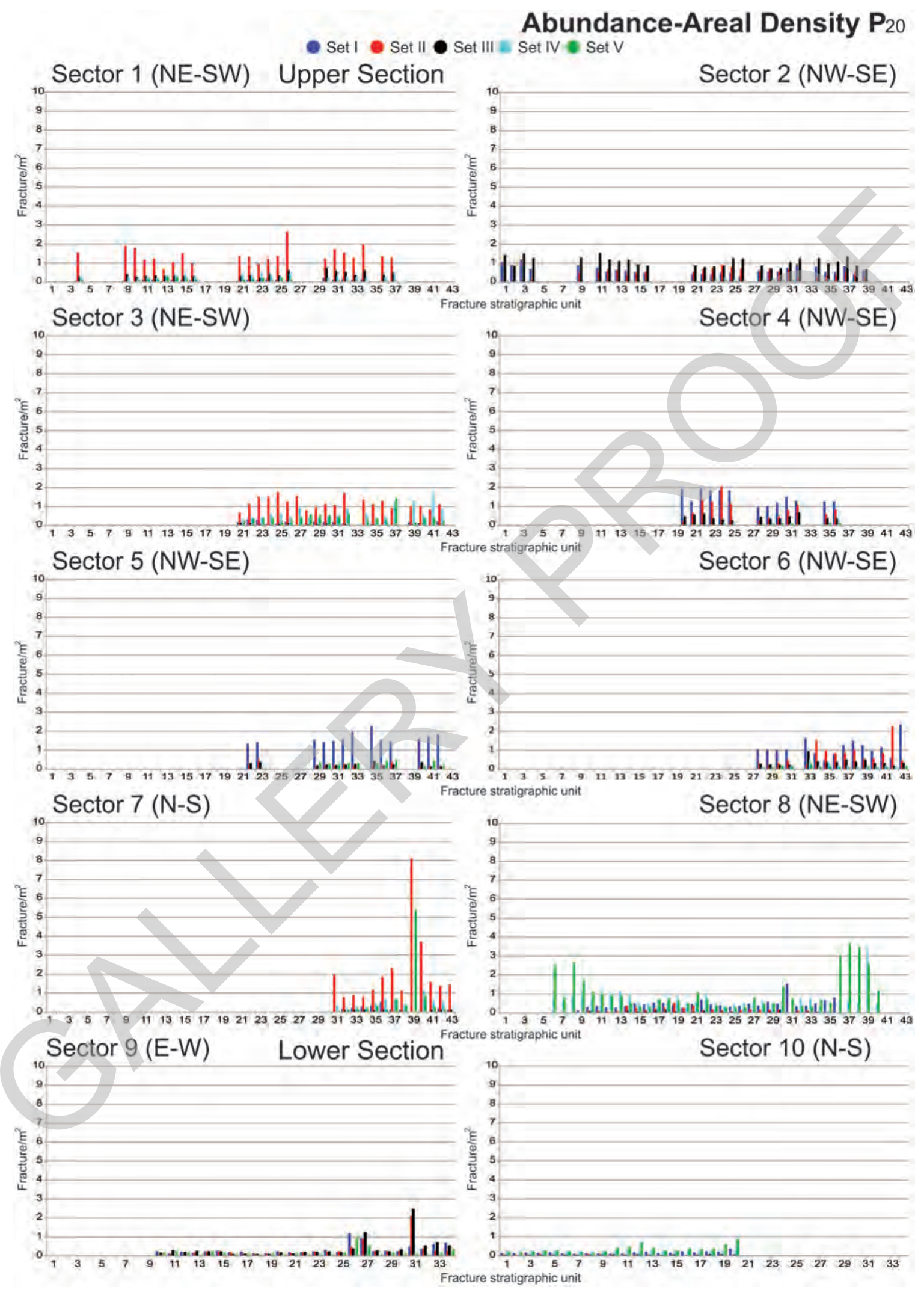

Figure 20. Abundance-Areal Density $\mathrm{P}_{20}$. Number of fracture centroids per surface exposed of fracture stratigraphic unit, by fracture orientation set and sector (Dershowitz and Herda, 1992). 


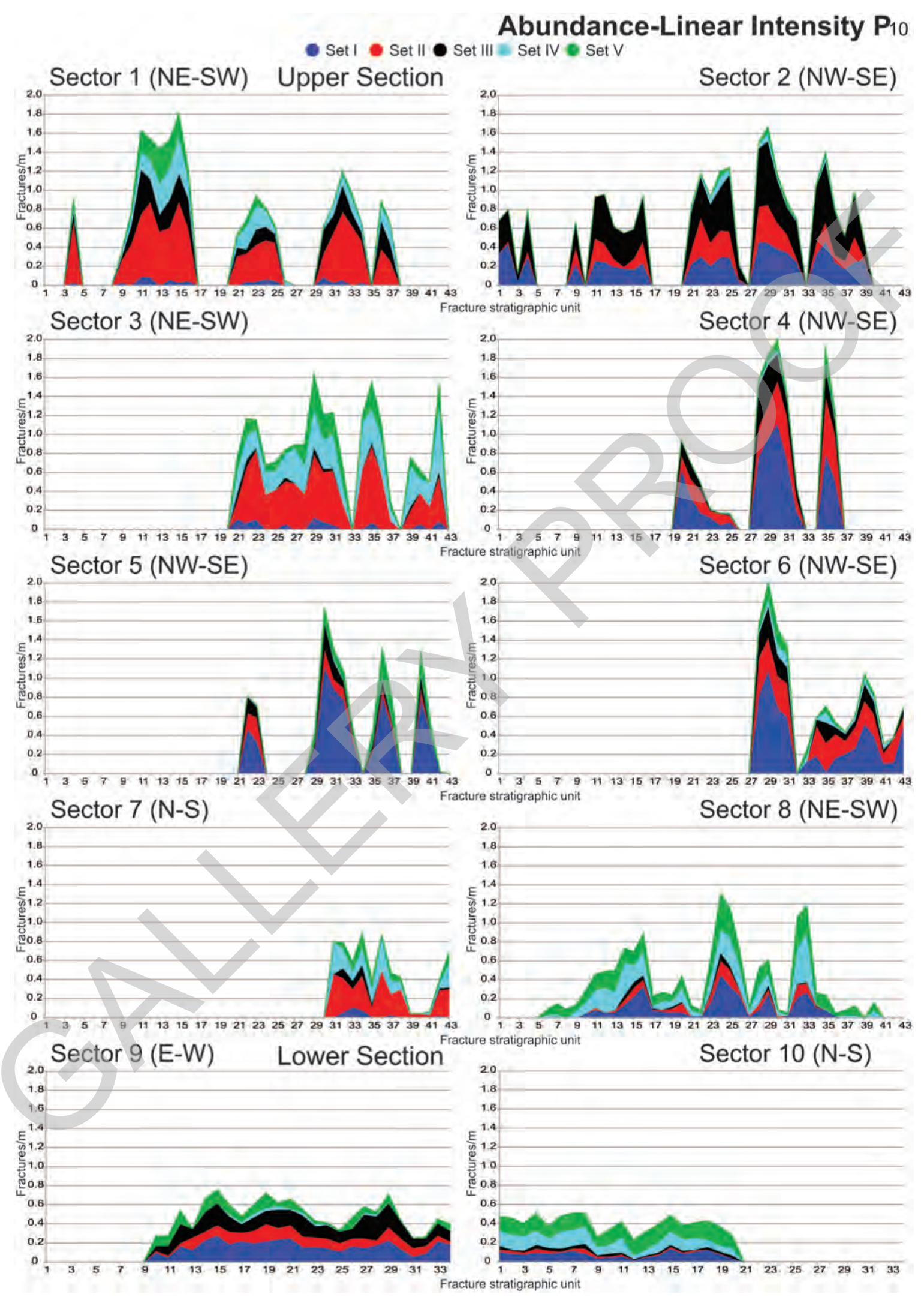

Figure 21. Abundance-Linear Intensity $P_{10}$. Number of fractures intersected per meter by the scanline in each fracture stratigraphic unit and by fracture orientation set in each sector (Dershowitz and Herda, 1992). 
and maximums of $1.8 \mathrm{fr} . / \mathrm{m}$ in sectors oriented northeast-southwest. Fracture set I has the highest abundance intensities with $1 \mathrm{fr} . / \mathrm{m}$ in several fracture stratigraphic units, followed by fracture sets II, III, and IV, which are predominant in some cases too.

In the lower section of the Huamampampa Formation, the abundance intensity is more regular with values around $0.4 \mathrm{fr} . / \mathrm{m}$. Fracture sets I, II, and III have higher intensities in sector 9 (oriented east-west; Figure 4) and fracture sets IV and V in sector 10 (oriented north-south; Figure 4).

The results for parameter $\mathrm{P}_{21}$ (Figure 22), trace length per area, are quite similar to the abundance intensities measured for $\mathrm{P}_{10}$. The highest values exceed $1 \mathrm{~m} / \mathrm{m}^{2}$, whereas the majority of the values are below $0.5 \mathrm{~m} / \mathrm{m}^{2}$. Fracture sets I and II have the highest $P_{21}$ values, with the exception of fracture set III in sector 2 (oriented northeast-southwest; Figure 4) and fracture set $\mathrm{V}$ for sectors 8 and 10 (oriented northeast-southwest and north-south, respectively; Figure 4).

Volumetric intensity measurements $\left(\mathrm{P}_{32} ;\right.$ Figures $23,24)$ are calculated with the conversion factors $\mathrm{C}_{13}$ and $\mathrm{C}_{23}$ (Wang, 2005); both results have similar shapes on the graphs, but their values differ. Values calculated with the conversion factor $C_{13}$ are higher and more heterogeneous (Figure 23) than those calculated with $\mathrm{C}_{23}$ (Figure 24). Most of the calculated $\mathrm{P}_{32}$ values are below $1 \mathrm{~m}^{2} / \mathrm{m}^{3}$ and, in some cases, reach $1.4 \mathrm{~m}^{2} / \mathrm{m}^{3}$ and exceptionally $2 \mathrm{~m}^{2} / \mathrm{m}^{3}$. The highest values are observed for fracture sets I and II in all sectors, with the same exceptions as for $\mathrm{P}_{21}$ in sectors 2, 8, and 10 (Figure 4) where the highest values are for fracture sets III and V (Figures 23, 24).

Porosity Fracture porosity represents the fracture space in the rock mass, as a percentage. Mean fracture aperture measured in the outcrop scanlines is $1 \mathrm{~mm}$ ( $0.4 \mathrm{in}$.); therefore, the linear, areal, and volumetric porosities, $\mathrm{P}_{11}, \mathrm{P}_{22}$ and $\mathrm{P}_{33}$, are calculated from this value. Fracture porosity is the product of the aperture by its linear $\mathrm{P}_{10}$, areal $\mathrm{P}_{21}$, and volumetric $\mathrm{P}_{32}$ intensities. In this way, the aperture is constant for all fracture sets. Graphs from intensities (Figures 20, 21, 23, 24) are valid for representing the distribution shapes of porosities in the fracture stratigraphic units by sectors and fracture sets.

The actual values for linear porosity $\mathrm{P}_{11}$ reach a maximum of $0.1 \%$ and $0.08 \%$ for fracture sets I and II, respectively. The overall linear porosity reaches $0.2 \%$ in sectors oriented northwest-southeast (sectors 2, 4, 5 , and 6; Figure 4), whereas it is lower in the rest of the upper section of the Huamampampa Formation. Area and volumetric porosities calculated in the sectors of the upper section of the Huamampampa Formation oscillate around $0.15 \%$.

\section{DISCUSSION}

The geological map (Figures 2,4) indicates the presence and distribution of the normal faults and fractures studied at the backlimb of the Abra del Condor anticline. Faults are oriented perpendicular to the fold axis with lengths of up to hundreds of meters, having small vertical displacements that cut the Huamampampa Formation and its fracture stratigraphic units. These faults are closely spaced and form clusters, called swarms or corridors (Peacock et al., 2016); there is more intensity near the anticline hinge. Analysis from virtual and outcrop scanlines reveals the coexistence of five fracture sets (Figures 8,9), of which sets I and II, arranged orthogonally, are dominant, attending to fracture intensity values (Figure 21). The strike of fracture set I is parallel to the regional shortening direction and perpendicular to the fold axis, although it is not maintained rigorously in the whole outcrop. Fracture set II is parallel to the fold axis, whereas the rest of fractures are fold-oblique. Fracture characterization (Figures 8-24) reveals a close relationship between fracture sets I and III in terms of size distributions, spacing, and abundance. This same relationship is also established for fracture sets IV and V, with respect to set II.

In relation to their genesis, fracture sets I and II are the consequence of changes to the stress regime that affected the studied area. Therefore, fracture sets I and II were formed during a prefolding extensional stress regime that was followed by a strike-slip stress regime (Zapata and Araujo, 2003), where set I was shear reactivated, inducing the growth of fracture zones and the generation of the rest of fracture sets as splay fractures. During folding, strike-slip, and reverse stress regimes, set II was reactivated as reverse shear fractures and thrust-related fractures. The postfolding regime induced trough-going splay fractures that affected the studied area (Florez-Niño et al., 2005; Iñigo et al., 2012).

The mechanical properties and layering of strata influence fracture development in a rock mass. Therefore, this is where the fractures must be characterized. It is a poor assumption to presume that the rock mass is homogeneous or greatly simplified (Zahm and Hennings, 2009). Burial and diagenesis vary in space and time during a given fracture's history (Laubach et al., 2009), hindering the identification of these units. To consider the present fracture intensity as a consequence of the previous mechanical properties and layering is a reasonable argument in order to identify the units and call them fracture stratigraphy units (Laubach et al., 2009). 


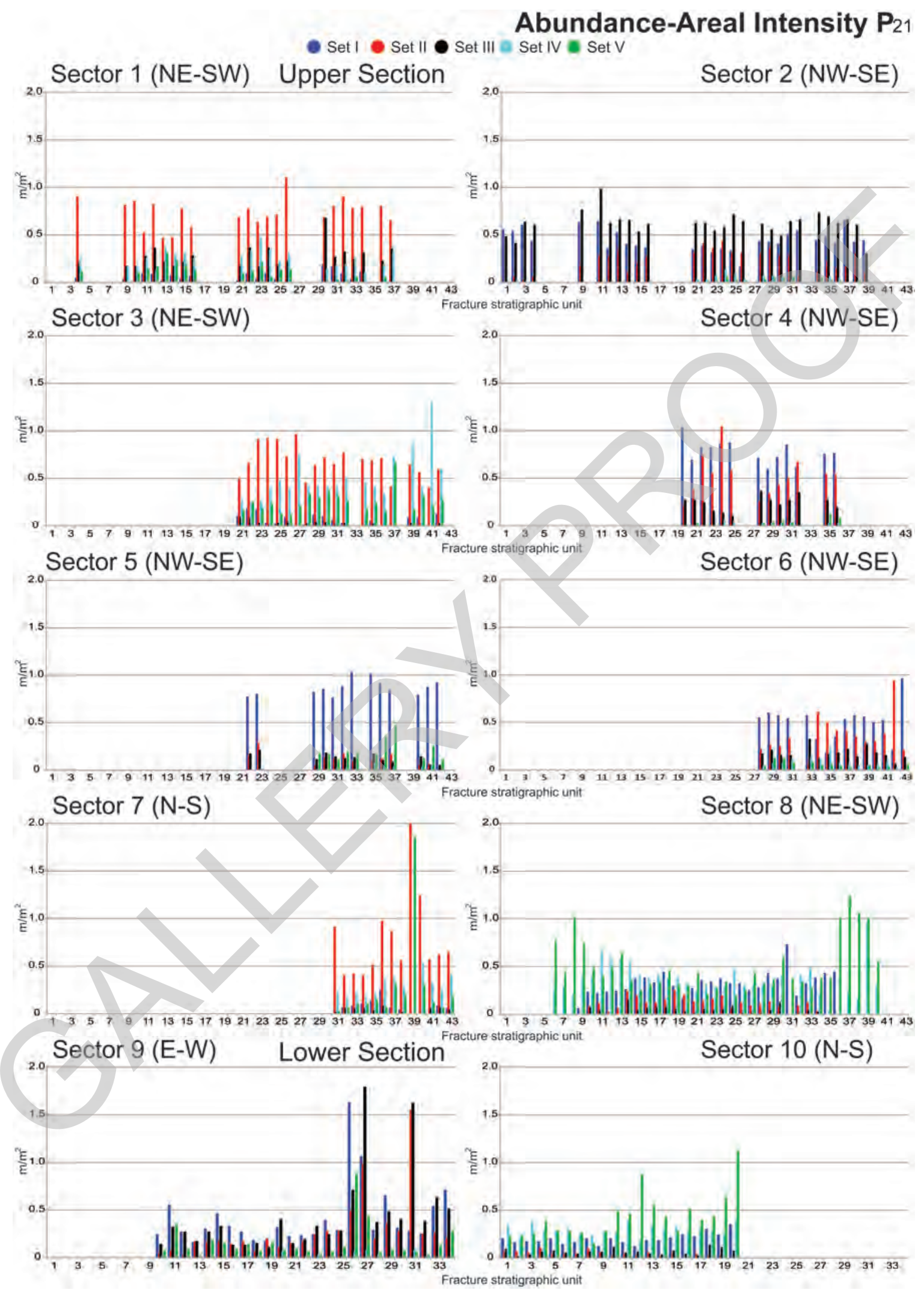

Figure 22. Abundance-Areal Intensity $\mathrm{P}_{21}$. Length of fracture per surface of fracture stratigraphic unit, measured by each fracture orientation set in each sector (Dershowitz and Herda, 1992). 


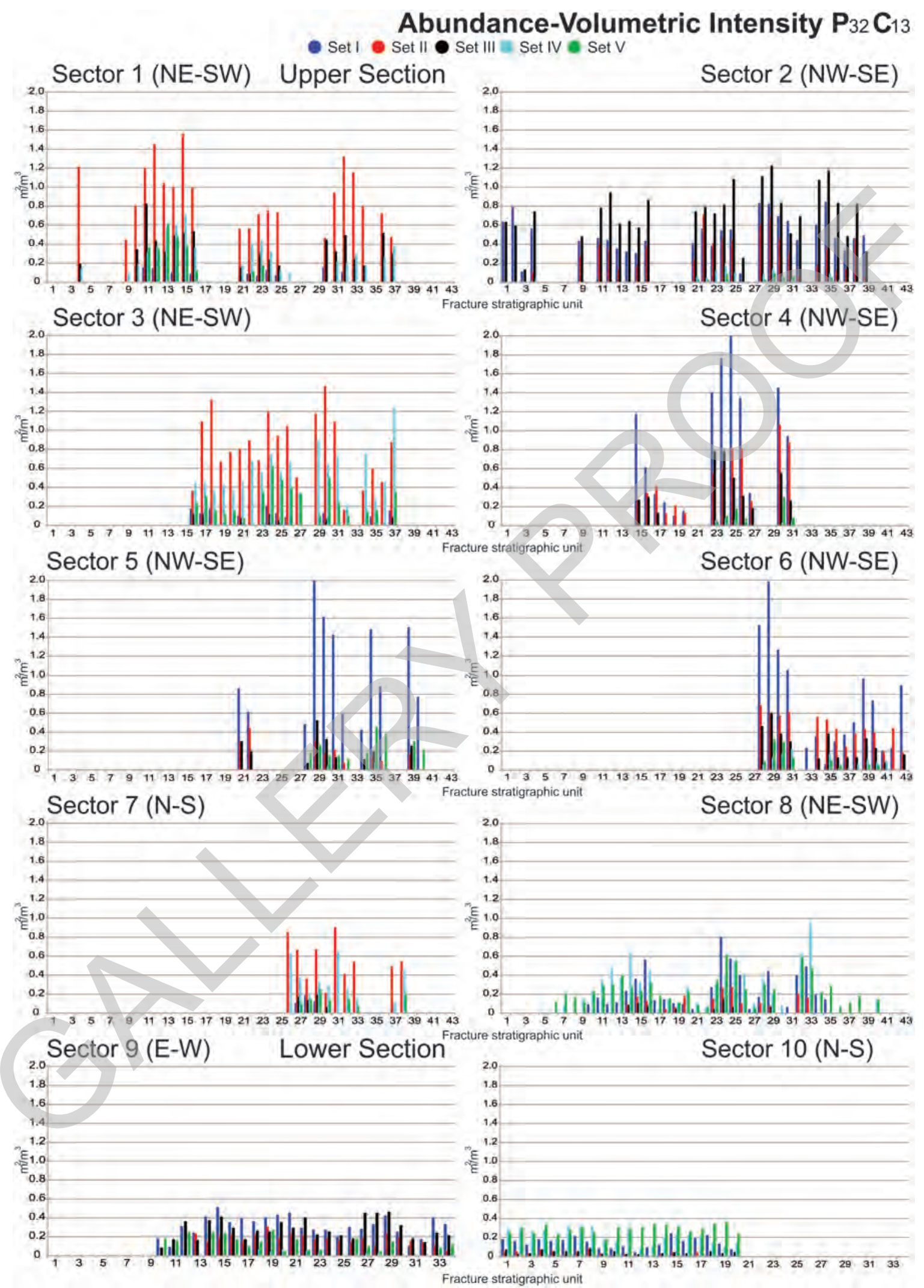

Figure 23. Abundance-Volumetric Intensity $\mathrm{P}_{32} \mathrm{C}_{13}$. Values correspond to the indirect measure of the fracture area per volume using the conversion factor $\mathrm{C}_{13}$ for each fracture stratigraphic unit and by each fracture orientation set in each sector (Dershowitz and Herda, 1992). 


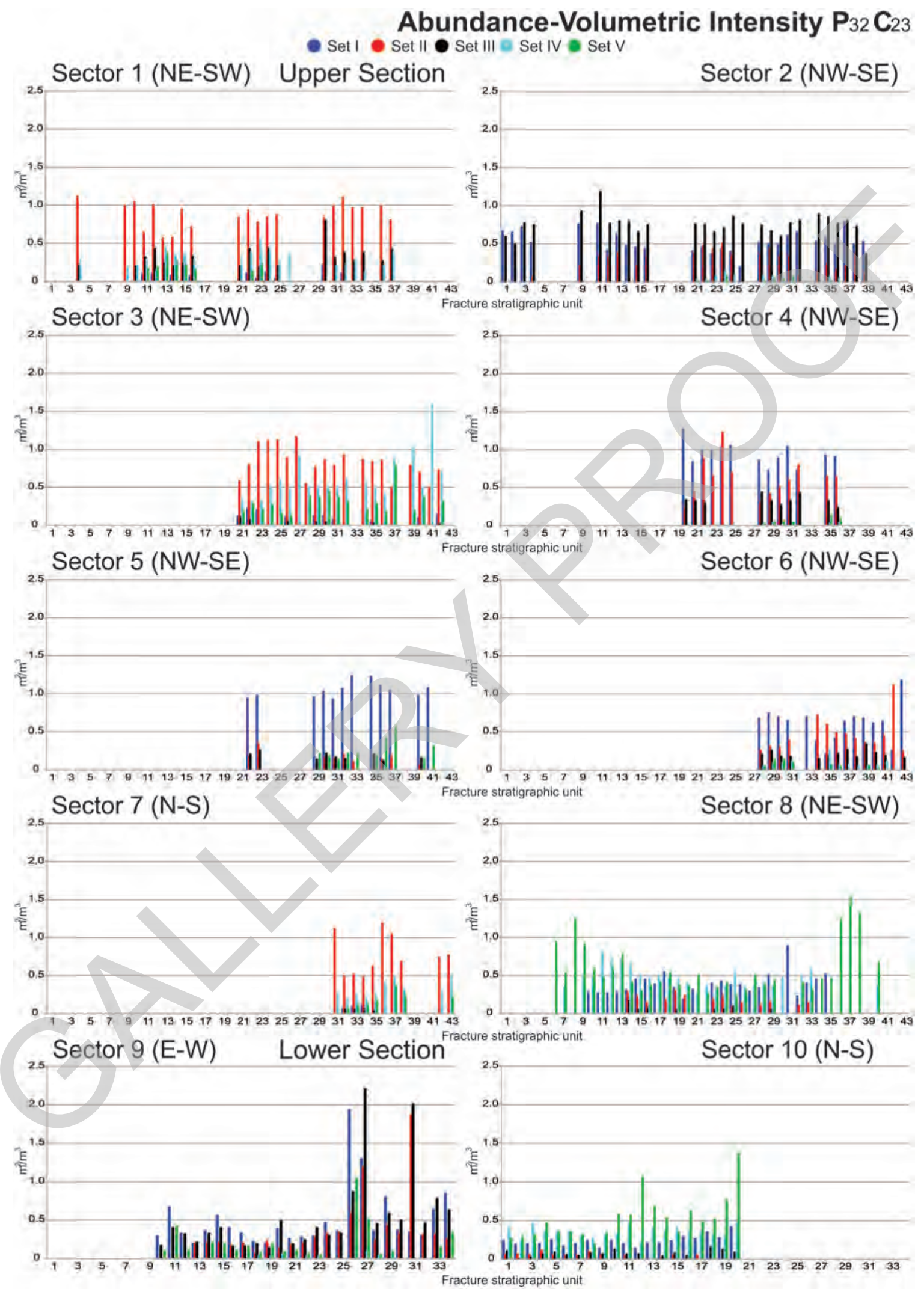

Figure 24. Abundance-Volumetric Intensity $\mathrm{P}_{32} \mathrm{C}_{23}$. Values correspond to the indirect measure of the fracture area per volume using the conversion factor $\mathrm{C}_{23}$ for each fracture stratigraphic unit and by each fracture orientation set in each sector (Dershowitz and Herda, 1992). 
Forty-four units in the upper section of the Huamampampa Formation and 34 units in the lower section of the Huamampampa Formation complete the subdivision of the outcrop in fracture stratigraphic units using the intensity as an attribute (Figures 6, 7). In general terms, characterization may be considered homogeneous with respect to sizes and abundances. The fracture stratigraphic units have similar values, always within small ranges, without highlighting any fracture stratigraphic unit that is independent of lithology. It is possible to assume that processes of burial and diagenesis have contributed to the rock mass homogenization, affecting and influencing fracture creation in the studied area (Laubach et al., 2009).

However, the fracture characterization reveals that the studied area is not so homogeneous with respect to its individual and collective properties presenting some differences (Table 6). The long extension of the surveyed area allows finding trends along the outcrop, which have been recorded and analyzed. In the Abra del Condor anticline, the most evident trend is a decrease in fracture intensity from the fold hinge toward the backlimb (Figures 2,4), that is, from sector 1 to sector 8 . The mean fracture intensity decreases gradually between these sectors, whereas the bedding dip increases from $0^{\circ}$ (hinge) to $30^{\circ}$ (backlimb) in the upper section of the Huamampampa Formation. Sectors 9 and 10 in the lower section of the Huamampampa Formation present the same trend (Figure 25). Therefore, fracture intensity is directly related to the structural position along the anticline profile and not with the lithology.

The mean thickness of fracture stratigraphic units for both sections of the Huamampampa Formation is $2.6 \mathrm{~m}$ $(8.5 \mathrm{ft})$, although there are units up to $4-6 \mathrm{~m}(13-20 \mathrm{ft})$, even up to $8 \mathrm{~m}(26 \mathrm{ft})$ in the lower section of the Huamampampa Formation (Figures 6, 7). Mean fracture heights generally are shorter than the thicknesses of the units in the outcrop (Figure 15) but not in units with thickness about $1 \mathrm{~m}(3 \mathrm{ft})$. The vertical persistence is not present in all units, but when it is accounted, it is $10-15 \%$ with the exception of sectors closer to the hinge fold (sectors 1 and 2; Figure 4) and sector 9 in the lower section of the Huamampampa Formation, where fracture heights are

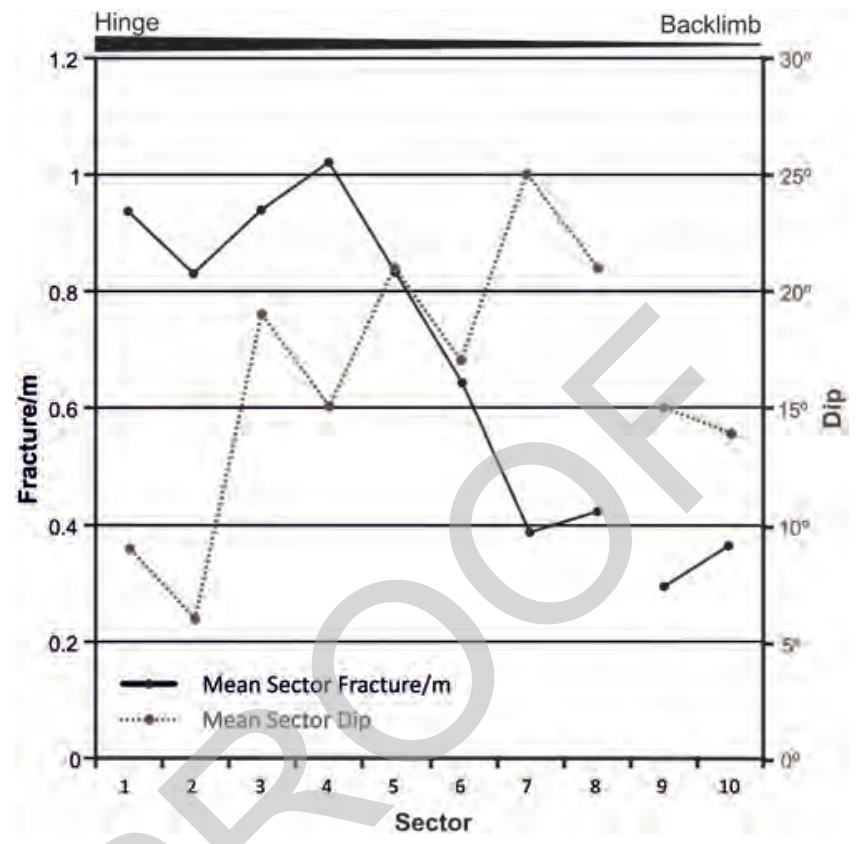

Figure 25. Plot showing the inverse relation between the mean fracture intensity for each sector (black line) and position with respect to fold represented by the bedding dip (gray dot lines). Bedding dip in sectors approaching the fold hinge are around $0^{\circ}$, whereas the distance to hinge increases; in the backlimb area, the bedding dip increases until $25^{\circ}$.

particularly higher. Therefore, our interpretation is that most of the fractures are confined to units but do not vertically span the unit thickness; only about a $10-15 \%$ (Figure 19) are developed in some units that exceed the boundaries. In the fracture-height classification categories from Hooker et al. (2013), fractures are included in the category Unbounded with a wide representation of confined fractures and quantifying the unbounded with the data of vertical persistence (Figure 19). Low FSRs and poor FSIs are in accord with these classifications (Figure 13) and may be more representative of classifications type Perfect bed-bounded or Hierarchicals (Hooker et al., 2013), with fractures totally confined from top to bottom. Fracture stratigraphic units that are free of vertical persistence are classified in the category Top-bounded, where the fractures end in the same unit but do not cross

Table 6. Mean fracture density measured along the multiples virtual scanlines for each sector.

\begin{tabular}{ccccccccc}
\hline Fracture Set & Sector 1 & Sector 2 & Sector 3 & Sectors 4, 5, and 6 & Sector 7 & Sector 8 & Sector 9 & Sector 10 \\
\hline I & 2.81 & 2.18 & 2.94 & 2.56 & 3.37 & 2.44 & 1.94 \\
II & 1.96 & 2.54 & 2.23 & 2.58 & 1.65 & 1.77 & 2.09 \\
III & 1.61 & 2.18 & 2.06 & 1.91 & 2.62 & 2.8 & 2.24 \\
IV & 1.91 & 2.27 & 1.86 & 2.11 & 1.77 & 1.99 & 2.33 \\
V & 1.47 & 1.71 & 2.19 & 2.29 & 1.78 & 2.14 & 2.19 \\
\hline
\end{tabular}


or cut both boundaries. Furthermore, the coefficient of variation describes the fracture distribution within the units as random with some data point clustering.

In this way, fracture stratigraphic unit thickness does not control the fracture distribution. Fractures were developed by randomly populating the unitsalthough some clustering is observed-but without being limited by the unit boundaries, with the exception of infrequent unit thicknesses around $1 \mathrm{~m}(3 \mathrm{ft})$.

Mean fracture lengths measured in the virtual frac-

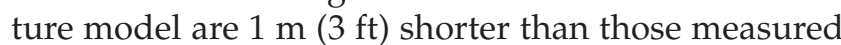
in outcrop scanlines. Clearly, the difference is due to the emplacement of the scanlines. Outcrop scanlines are measured in the top of the layers, and the virtual scanlines are measured perpendicular to the top of the layer (on the cliffs) obscuring the total fracture lengths. However, this result is nonetheless coherent with the scanline and outcrop orientations. Measurements of fracture length in the study area reveal metric lengths, with the outcrop scanlines showing maximums of tens of meters.

Normal faults recognized in the study area with north-south orientations are commonly formed on contractional anticlines (Morris et al., 2012; Ferrill et al., 2017) and are perpendicular to the dominant structures present in the Abra del Condor anticline and the thrust sheet of Piedra Larga. Faults in the Abra del Condor described previously by Florez-Niño et al. (2005) and Iñigo et al. (2012) were incorporated in this study and were subdivided into three categories: fault zones, intermediate, and small faults. These types of normal faults can have influence in different ways, increasing or decreasing the fracture connectivity. Decreasing fracture connectivity can be produced when damaged zones play a sealing mechanism between fractures that reduce the lateral permeability of the rock mass. In the study area, the damage zone is in the backlimb around the hinge zone, where the fracture intensity is higher. For the case of increasing fracture connectivity, this can be produced by the mechanical discontinuity of the fault. Instead, intermediate and small faults can act as conduits, increasing the connectivity owed to longer faults in areas of minor fracture intensity but with similar aperture as the damaged zones. In the above scenario (supports higher fracture intensities), it is the length of the faults that plays a more significant role in fractured reservoir connectivity and permeability. What was observed in the Abra del Condor is that, away from the backlimb area close to the hinge, a larger drainage area or connectivity was present due to longer faults. Lateral permeability and connectivity in damaged zones and faults must be studied with more detail to assure which fault types compartmentalize the area. The possibility to act as conduits or seals depends on the length, height, aperture, or in-filling of these mechanical discontinuities, not only their presence.

Abundant scanline measurements are dependent on the sampled outcrop orientation, with the exception of the volumetric parameters, which are extrapolated from linear or aerial measurements in order to cover the volume. Volumetric intensity, or $\mathrm{P}_{32}$ values, calculated in the study area differs depending on the sector analyzed; consequently, the $360^{\circ}$ extrapolation to achieve a 3D measurement continues to be dependent on the scanline orientation. For this reason, it is most efficient to analyze $\mathrm{P}_{32}$ values by fracture set within more favorable orientation sectors. $\mathrm{P}_{32} \mathrm{C}_{13}$ and $\mathrm{P}_{32} \mathrm{C}_{23}$ maintain similar range magnitudes, except for several units with higher values. However, $\mathrm{P}_{33}$, or fracture porosity, has been calculated at $0.15 \%$, within of the range of $0-0.67 \%$, calculated by Iñigo et al. (2012) for the Abra del Condor sandstones.

Primary measured porosity is considered very low (Iñigo, 2009), and the fracture presence increases the total porosity although perhaps heterogeneously. This fracture characterization may be used as an input into a Discrete Fracture Network (DFN) or simulators to calculate the effective permeability of the system (Olson et al., 2009).

Results presented in this study allow the fracture analysis of the outcrop to be individualized for each fracture stratigraphic unit and for each fracture set, with the exception of the attribute distribution graphs. The semiautomatic processing data use the full capability of TLS and extend the virtual samples to inaccessible areas for other techniques. Software development continues to evolve based on the recognition of surfaces, like other authors (Zahm and Hennings, 2009; Wilson et al., 2011) although with the sacrifice that the fractures are exposed by traces (Geyer et al., 2015). Fracture digitization by traces is an alternative albeit slow method limited by the image perspective.

\section{CONCLUSIONS}

This methodology can be used in larges or inaccessible outcrops to characterize fractures where there are enough fractures to give reliable statistics. The analyses of these results are useful for making decisions about the field development, as in this case of the Subandean gas field.

Fracture characterization is based on the virtual fracture model created from TLS data and is complemented by fieldwork scanlines. Five fracture orientation sets populate the sandstones and shales of the 
Huamampampa Formation at the backlimb of the Abra del Condor anticline with two dominant orthogonal cross-fracture sets.

Fracture intensities have been used to identify 44 fracture stratigraphic units for the upper section of the Huamampampa Formation and 34 for the lower section of the Huamampampa Formation. The high degree of unit homogenization may be due to burial and diagenetic processes. In general, for the whole outcrop, the fracture intensity can be considered to be low with a mean of $1 \mathrm{fr}$. $/ \mathrm{m}$. This study supports fracture distribution and orientation tied to the structural control across the fold with higher intensities at the hinge. A low degree of fracture confinement for the fracture stratigraphic units is observed, as most of the fractures are shorter than the fracture stratigraphic unit thicknesses.

TLS and especially the strategy used to identify fractures at the outcrops allow contributing a huge data set to strengthen and improve fracture characterization.

The mean fracture intensity of $2.6 \mathrm{fr} . / \mathrm{m}$ is higher than TLS data results due to the upper range of scale detection for the visual scanlines methodology.

\section{ACKNOWLEDGMENTS}

This research was carried out by Geomodels Research Institute and REPSOL and was cofinanced by REPSOL and for hardware and software development by the projects CGL2014-54118-C2-1-R and CGL2013-40828-R from the Spanish Ministry of Science and Technology. We acknowledge Midland Valley and Paradigm for their software Move ${ }^{\mathrm{TM}}$ and Gocad ${ }^{\mathrm{TM}}$. We also would like to give thanks to YPFB for their permission to publish this paper and to the staff of REPSOL Bolivia for their kind support during the fieldwork. Our special recognition goes to Asterio Ayaviri for his contribution in the field trip. We thank the editor, Gonzalo Zamora, for his help. The manuscript benefited from reviewers D. A. Ferrill and an anonymous reviewer. English editing has been done by Grant George Buffett.

\section{REFERENCES}

Albariño, L., A. Dalenz Farjat, L. Álvarez, R. Hernández, and M. Pérez Leyton, 2002, Las secuencias sedimentarias del Devónico en el Subandino Sur y el Chaco. Bolivia y Argentina in Congreso de Exploración y Desarrollo de Hidrocarburos, no. 5, CD-ROM, Trabajos Técnicos, Mar de Plata, Argentina.

Baby, P., G. Hérail, R. Salinas, and T. Sempere, 1992, Geometry and kinematic evolution of passive roof duplexes deduced from cross section balancing: Example from the foreland thrust system of the southern Bolivian Subandean zone: Tectonics, v. 11, p. 523-536.

Bertotti, G., N. Hardebol, J. K. Taal-van Koppen, and S. M. Luthi, 2007, Toward a quantitative definition of mechanical units: New techniques and results from an outcropping deep-water turbidite succession (Tanqua-Karoo Basin, South Africa): AAPG Bulletin, v. 91, p. 1085-1098.

Bonnet, E., O. Bour, N. E. Odling, P. Davy, I. Main, P. Cowie, and B. Berkowitz, 2001, Scaling of fracture systems in geological media: Reviews of Geophysics, v. 39, p. 347-383.

Crowell, J. C., R. Suárez Soruco, and A. C. RochaCampos, 1981, The Silurian Cancañiri (Zapla) Formation of Bolivia, Argentina and Peru, in M. J. Hambrey and W. B. Harland, eds., The earth's pre-pleistocene glacial record: Cambridge University Press, Cambridge, p. 902-907.

Cruz, C., J. Oller Veramendi, M. Di Benedetto, M., Pereira, and H. Villar, 2008, Los sistemas petroleros devónicos del Subandino Sur y Pie de Monte de la cuenca de Tarija, Bolivia, in C. Cruz, J. Rodriguez, J. Hechem, and H. Villar, eds., Sistemas Petroleros de las Cuencas Andinas: VII Congreso de Exploración y Desarrollo de Hidrocarburos, Instituto Argentino del Petróleo y el Gas, p. 159-187.

Dershowitz, W. S., and H. H. Herda, 1992, Interpretation of fracture spacing and intensity, in J. R. Tillerson and W. R. Waversik, ed., Rock mechanics: Rotterdam, Balkema, p. 757-766.

Dunn, J. F., K. G. Hartshorn, and P. W. Hartshorn, 1995, Structural styles and hydrocarbon potential of the Subandean thrust belt of southern Bolivia, in A. J. Tankard, R. Suárez-Soruco, and H. J. Welsink, eds., Petroleum basins of South America: AAPG Memoir 62, p. 523-543.

Echavarria, L., R. Hernández, R. Allmendinger, and J. Reynolds, 2003, Subandean thrust and fold belt of northwestern Argentina: Geometry and timing of the Andean evolution: AAPG Bulletin, v. 87, p. 965-985.

Ferrill, D. A., R. N. McGinnis, A. P. Morris, K. J. Smart, Z. T. Sickmann, M. Bentz, D. Lehrmann, and M. A. Evans, 2014, Control of mechanical stratigraphy on bed restricted jointing and normal faulting: Eagle Ford Formation, south-central Texas, U.S.A.: AAPG Bulletin, v. 98, p. 2477-2506.

Ferrill, D. A., A. P. Morris, R. N. McGinnis, K. J. Smart, S. S. Wigginton, and N. J. Hill, 2017, Mechanical stratigraphy and normal faulting: Journal of Structural Geology, v. 94, p. 275-302.

Florez-Niño, J. M., A. Aydin, G. Mavko, M. Antonellini, and A. Ayaviri, 2005, Fault and fracture system in a fold and thrust belt: An example from Bolivia: AAPG Bulletin, v. 34, p. 471-493.

García-Sellés, D., O. Falivene, P. Arbués, O. Gratacós, S. Tavani, and J. A. Muñoz, 2011, Supervised identification and reconstruction of near-planar geological surfaces from terrestrial laser scanning: Computers \& Geosciences, v. 37, p. 1584-1594.

García-Sellés, D., P. Granado, O. Gratacós, and J. A. Muñoz, 2016, Geometrical characterization of fracture systems in rock mass by means of terrestrial laser scanner, in 
International Conference and Exhibition: AAPG/Society of Exploration Geophysicist, Barcelona, Spain, April 3-6, p. 234-234.

Geyer, A., D. García-Sellés, D. Pedrazzi, S. Barde-Cabusson, J. Martí, and J. A. Muñoz, 2015, Studying monogenetic volcanoes with a terrestrial laser scanner: Case study at Croscat volcano (Garrotxa Volcanic Field, Spain): Bulletin of Volcanology, v. 77, p. 1-14.

Gillespie, P. A., J. D. Johnston, M. A. Loriga, K. J. W. McCaffrey, J. J. Walsh, and J. Watterson, 1999, Influence of layering on vein systematics in line samples, in K. J. W. McCaffrey, L. Lonergan, and J. J. Wilkinson, ed., Fractures, fluid flow and mineralization: London, Geological Society, Special Publications 155, p. 36-56.

Gillespie, P. A., J. J. Walsh, C. G. Bonson, T., and Manzocchi, 2001, Scaling relationship of joint and vein arrays from The Burren, Co. Clare, Ireland: Journal of Structural Geology, v. 23, p. 183-201.

Gross, M. R., 1993, The origin and spacing of cross joints: Examples from Monterrey Formation, Santa Barbara Coastline, California: Journal of Structural Geology, v. 15, p. 737-751.

Hancock, P. L., 1985, Brittle microtectonics: Principles and practice: Journal of Structural Geology, v. 7, p. 437-457.

Hanks, C. L., J. C. Lorenz, and A. P. Krumhardt, 1994, Mechanical stratigraphy of the Lisburne group, Eastern Sadlerochit mountains: A preliminary report of field results, Department of Natural Resources: Division of Geological \& Geophysical Surveys, State of Alaska, Public-Data File 94-19. P. 26.

Hooker, J. N., S. E. Laubach, and R. Marrett, 2013, Fractureaperture size-frequency, spatial distribution, and growth processes in strata-bounded and non-stratabounded fractures, Cambrian Mesón Group, NW Argentina: Journal of Structural Geology, v. 54, p. 54-71.

Iñigo, J. F., 2009, Structural model and fracture analyses for major gas emplacement in Devonian sandstones of the Subandes, M.S. Thesis, The University of Texas, Austin, Texas, $297 \mathrm{p}$.

Iñigo, J. F., S. E. Laubach, and J. N. Hooker, 2012, Fracture abundance and patterns in the Subandean fold and thrust belt Devonian Huamampampa Formation petroleum reservoirs and outcrops, Argentina and Bolivia: Marine and Petroleum Geology, v. 35, p. 201-218.

Isaacson, P. E., and P. E. Sablock, 1987, Devonian system in Bolivia, Peru, and northern Chile: Second Canadian Society of Petroleum Geologists: Devonian System International Symposium, v. 1, p. 719-728.

Kley, J., A. H. Gangui, and D. Krüguer, 1996, Basementinvolved blind thrusting in the eastern Cordillera Oriental, southern Bolivia: Evidence from cross-sectional balancing, gravimetric and magnetotelluric data: Tectonophysics, v. 259, p. 171-184.

Labaume, P., S. M. F. Sheppard, and I. Moretti, 2001, Fluid flow in cataclastic thrust fault zones in sandstones, Sub-Andean zone, southern Bolivia: Tectonophysics, v. 340, p. 141-172.

Laubach, S. E., J. E. Olson, and M. R. Gross, 2009, Mechanical and fracture stratigraphy: AAPG Bulletin, v. 93 , p. 1413-1426.
Lohman, H. H., 1970, Outline of tectonic history of Bolivian Andes: AAPG Bulletin, v. 54, p. 735-757.

Moretti, I., P. Baby, E. Mendez, and D. Zubieta, 1996, Hydrocarbon generation in relation to thrusting in the Sub Andean zone from 18 to $22^{\circ} \mathrm{S}$, Bolivia: Petroleum Geoscience, v. 2 , p. $17-28$.

Moretti, I., P. Labaume, M. F. Sheppard, and J. Boulègue, 2002, Compartmentalisation of fluid migration pathways in the sub-Andean zone, Bolivia: Tectonophysics, v. 348, p. 5-24.

Morris, A. P., K. J. Smart, D. A. Ferrill, N. E. Reish, and P. F. Cowell, 2012, Fault compartmentalization in clastics reservoirs: AAPG Bulletin, v. 96, p. 1001-1015.

Narr, W., and J. Suppe, 1991, Joint spacing in sedimentary rocks: Journal of structural Geology, v. 13, p. 1037-1048.

Nelson, R. A., 2001, Geologic analysis of naturally fractured reservoirs, 2nd ed.: Houston, Gulf Publishing, 320 p.

Olson, J. E., Laubach, S. E. and R. H. Lander, 2009, Natural fracture characterization in tight gas sandstones: Integrating mechanics and diagenesis: Mechanical and fracture stratigraphy: AAPG Bulletin, v. 93, p. 1535-1549.

Peacock, D. C. P., C. W. Nixon, A. Rotevatn, D. J. Sanderson, and L. F. Zuluaga, 2016, Glossary of fault and other fracture networks: Journal of Structural Geology, v. 92, p. $12-29$.

Petit, J.-P., G. Massonnat, F. Pueo, and K. Rawnslae, 1994, Rapport de forme des fractures de Mode I dans les roches stratifies: Une étude de cas dans le bassin Permien de Lodève (France): Bulletin du Centres Recherches Exploraion-Production: Elf Aquitaine, v. 18, p. 211-229.

Pollard, D., and A. Aydin, 1988, Progress in understanding jointing over the past century: Geological Society of America Bulletin, v. 100, p. 1181-1204.

Priest, S. D., 1993, Discontinuity analysis for rock engineering: London, Chapman \& Hall, 473 p.

Rocha, E., and E. O. Cristallini, 2015, Controls on structural styles along the deformation front of the Subandean zone of southern Bolivia: Journal of Structural Geology, v. 73, p. 83-96, DOI: 10.1016/j.jsg.2015.02.010.

Santana, D., J. Corominas, O. Mavrouli, and D. García-Sellés, 2012, Magnitude-frequency relation for rockfall scars using a Terrestrial Laser Scanner: Engineering Geology, v. $145-146$, p. $50-64$

Schmitz, M., and J. Kley, 1997, The geometry of the central Andean backarc crust: Joint interpretation of cross section balancing and seismic refraction data: Journal of South American Earth Sciences, v. 10, p. 99-110.

Seers, T. D., and D. Hodgetts, 2014, Comparison of digital outcrop and conventional data collection approaches for the characterization of naturally fractured reservoirs analogues: London, Geological Society, Special Publications 2014, v. 374, p. 51-77.

Sempere, T., 1995, Phanerozoic evolution of Bolivia and adjacent regions, in A. J. Tankard, R. Suárez-Soruco, and H. J. Welsink, eds., Petroleum basins of South America: AAPG Memoir 62, p. 207-230.

Slob, S., H. R. G. K. Hack, B. van Knapen, K. Turner, and K. Kemeny, 2005, A method for automated discontinuity analysis of rock slopes with 3D laser scanning, in 
586

GARCÍA-SELLÉS ET AL.

Proceedings of the transportation research board 84th annual meeting, January 9-13, Washington, DC, 16 p.

Sturzenegger, M., and D. Stead, 2009, Quantifying discontinuity orientation and persistence on high mountain rock slopes and large landslides using terrestrial remote sensing techniques: Natural Hazards and Earth system Sciences, v. 9, p. 267-287.

Suárez-Soruco, R., 1995, Comentarios sobre la edad de la formación Cancañiri: Revista Técnica de Yacimientos Petrolíferos Fiscales de Bolivia, v. 16, no. 1-2, p. 51-54.

Toro, M., 1994, Los trilobites hirnantianos de la Formación Cancañiri: Memorias del XI Congreso Geológico de Bolivia, Santa Cruz, Bolivia, p. 260-264.

Vistalli, M., 1999, Cuenca siluro-devónica, in G. Gonzáles, J. Omarini, and I. Viramonte, eds., Geología del Noroeste Argentino: XIV Congreso Geológico Argentino, p. $168-184$.
Wang, X., 2005, Stereological interpretation of rock fracture traces on borehole walls and other cylindrical surfaces, M.S. Thesis, Virginia Polytechnic Institute and State University, Virginia, $123 \mathrm{p}$.

Wilson, C., A. Aydin, M. Karimi-Fard, L. Durlofsky, A. Sagy, E. Brodsky, O. Kreylos, and L. Kellog, 2011, From outcrop to flow simulation: Constructing discrete fracture models from a LIDAR survey: AAPG Bulletin, v. 95, p. 1183-1905.

Zahm, C., and H. Hennings, 2009, Complex fracture development related to stratigraphic architecture: Challenges for structural deformation prediction, Tensleep sandstone at the Alcova anticline, Wyoming: AAPG Bulletin, v. 93, p. 1427-1446.

Zapata, T., and H. Araujo, 2003, Discrete fracture characterization applied to the Margarita field, Bolivia: VIII Simposio Bolivariano-Exploracion Petrolera en las Cuencas Subandinas, p. 170-179.

00000 ch21 rev02 551-586.indd 586

06/09/18 7:04 PM 